\title{
A Review of Mid-Infrared Supercontinuum Generation in Chalcogenide Glass Fibers
}

\author{
Shixun Dai *, Yingying Wang, Xuefeng Peng, Peiqing Zhang, Xunsi Wang and Yinsheng Xu \\ Laboratory of Infrared Material and Devices, The Research Institute of Advanced Technologies, \\ Ningbo University, Ningbo 315211, China; wangyingying127@163.com (Y.W.); pengxuefeng@nbu.edu.cn (X.P.); \\ zhangpeiqing@nbu.edu.cn (P.Z.); wangxunsi@nbu.edu.cn (X.W.); xuyinsheng@nbu.edu.cn (Y.X.) \\ * Correspondence: daishixun@nbu.edu.cn; Tel: +86-574-8760-0947
}

Received: 31 March 2018; Accepted: 25 April 2018; Published: 3 May 2018

\begin{abstract}
Chalcogenide glasses have the advantages of a wide transparency window (over $20 \mu \mathrm{m}$ ) and high optical nonlinearity (up to a thousand times greater than that of silica glasses), making them good candidates for mid-infrared supercontinuum generation. In this review, we describe both the history and recent developments in mid-infrared supercontinuum generation from chalcogenide fibers according to three kinds of fiber structures: step-index, microstructured and tapered fibers. We also review the coherence properties of mid-infrared supercontinuum generation and all-fiber supercontinuum sources based on chalcogenide fibers.
\end{abstract}

Keywords: chalcogenide glass fiber; mid-infrared; nonlinear optics; supercontinuum generation

\section{Introduction}

Supercontinuum (SC) generation has been studied extensively in various nonlinear media (including solids, liquids, gases and diverse types of waveguides) since 1970, when it was first reported in bulk glass by Alfano et al. [1]. In optical fibers, SC generation originates from the interaction of a ultrashort laser pulse with the dispersion and nonlinearity of the fiber [2]. SC sources with spatial coherence, broad bandwidth, and high brightness have received considerable attention due to their significant potential in various applications, such as spectroscopy [3], hyperspectral microscopy [4], and spectral tissue imaging [5]. In particular, the mid-infrared spectral region (MIR, usually refers to the $2-5 \mu \mathrm{m}$ range) is regarded an important topic because most molecules exhibit fundamental vibrational absorption bands in this region, leaving distinctive spectral fingerprints which are critical for applications, such as biomedical science [6], sensing [7], and defense and security [8].

Various soft-glass fibers made of fluoride [9-11], tellurite [12-14], and chalcogenide (ChG) glasses [15-17] have been used to generate MIR SCs, and numerous achievements have been accomplished. Fluoride and tellurite are both transparent in the wavelength range below $5.5 \mu \mathrm{m}$ and thus, cannot be used for wavelengths longer than $5.5 \mu \mathrm{m}$. In contrast, $\mathrm{ChG}$ glasses have comparatively wider transparency window (over $20 \mu \mathrm{m}$ ) [18] and higher optical nonlinearity (up to a thousand times greater than that of silica glasses) [19], making them good candidates for MIR SC generation. The ability to control fiber dispersion is significant because it can provide pump conditions with relatively greater flexibility for SC generation. The technology of microstructured optical fibers (MOF) and tapering is widely used to blue-shift the zero dispersion wavelengths (ZDWs) of ChG fibers, and offers increased nonlinear coefficients, which lead to broadband SC generation in the MIR by using relatively shorter pump wavelengths with lower pump powers [20].

This paper is structured as follows: In Section 2, we briefly review the features of ChG glasses and transmission loss, dispersion, and nonlinearity of ChG fibers. In Section 3, SC generation in the ChG step-index, MOF, and tapered fibers are reviewed to clarify their developments in recent years. 
In Sections 4 and 5, the coherence of SC generation and its progress toward all-fiber SC sources based on ChG fibers are also described. In Section 6, our conclusions are drawn, and prospects are presented.

\section{ChG Glasses and Fibers}

\subsection{Overview of ChG Glasses}

ChG glasses are a non-oxide class of glasses that are mainly composed by one or more chalcogen elements in group VIA of the periodic table, such as sulfur (S), selenium (Se), and tellurium (Te), in combination with other metalloid elements (arsenic (As), antimony (Sb), germanium (Ge), etc.) [21]. ChG glasses have been known for more than half a century as infrared (IR) optical materials.

Table 1 lists the typical optical parameters of silica and several IR glasses [22]. Several significant features of $\mathrm{ChG}$ glasses have made them attractive in the MIR range. A highly important property of ChG glasses is their broad IR transparency range, which extends the long wavelength cut-off edge from 12 to $20 \mu \mathrm{m}$ depending on the mass of anionic elements present in the ChG glasses (viz. $\mathrm{S}$, Se, and Te, as shown in Figure 1) [18] covering the third atmospheric transmitting window. The IR coverage of $\mathrm{ChG}$ glasses implies potential applications in remote or (bio)chemical sensors and optical communication systems with limitless capacity $[7,23]$. ChG glasses possess a high third-order optical nonlinearity up to a thousand times greater than that of silica glasses $[19,24,25]$, attributed to their high refractive indices $\left(\sim 2.9\right.$ for $\mathrm{As}_{2} \mathrm{Se}_{3}$ and $\sim 2.5$ for $\left.\mathrm{As}_{2} \mathrm{~S}_{3}\right)$. Furthermore, low phonon energies, a long multiphoton absorption edge [26], and high power handling also make ChG glasses excellent candidates for MIR nonlinear optics.

Table 1. Typical optical parameters of silica and several infrared (IR) glasses.

\begin{tabular}{ccccc}
\hline Glass & Refractive Index & $\mathbf{n}_{\mathbf{2}} / \mathbf{n}_{\mathbf{2}}$ (Silica) $^{\mathbf{1}}$ & Transmission Range $(\boldsymbol{\mu m})^{\text {ZDW }(\boldsymbol{\mu m})}$ \\
\hline Silica & 1.44 & 1.0 & $0.2-3.5$ & 1.26 \\
ZBLAN $^{2}$ glass & 1.49 & 1.2 & $0.5-5.5$ & 1.71 \\
Tellurite glass & 2.03 & 19 & $0.5-4.5$ & 2.13 \\
$\mathrm{As}_{2} \mathrm{~S}_{3} \mathrm{ChG}$ & 2.5 & 200 & $0.6-12$ & 4.8 \\
$\mathrm{As}_{2} \mathrm{Se}_{3} \mathrm{ChG}$ & 2.9 & 600 & $1.0-16$ & 7.5 \\
Te-based ChG & $\sim 3.2$ & $\sim 1000$ & $1.5-25$ & $>7.5$ \\
\hline
\end{tabular}

${ }^{1} \mathrm{n}_{2}$, nonlinear refractive index; ${ }^{2} \mathrm{ZBLAN}, \mathrm{ZrF}_{4}-\mathrm{BaF}_{2}-\mathrm{LaF}_{3}-\mathrm{AlF}_{3}-\mathrm{NaF}$.

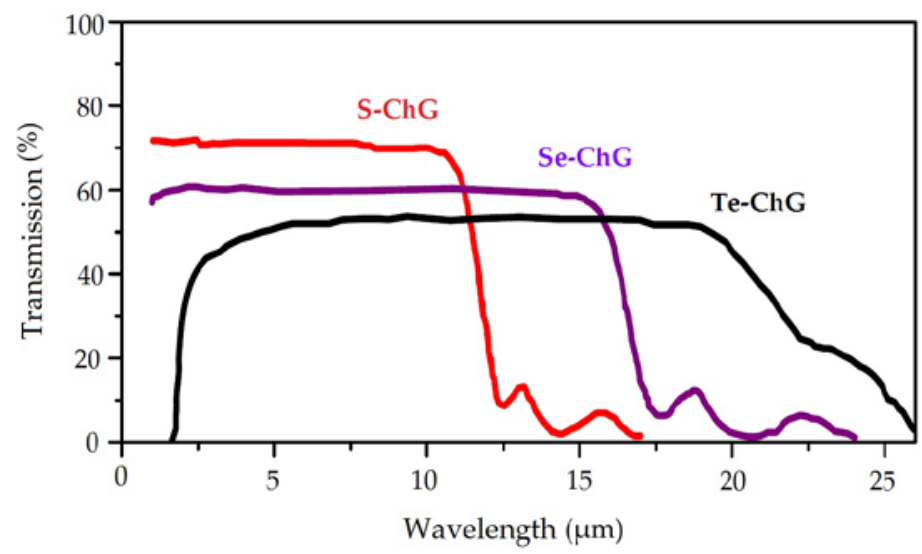

Figure 1. Typical infrared (IR) transmission spectra of millimeter-thick S-, Se-, and Te-based chalcogenide $(\mathrm{ChG})$ bulk samples (reproduced with permission from [22], copyright Optical Society of America, 2015).

\subsection{Overview of ChG Fibers}

The first ChG fiber was reported in 1960s and was made of $\mathrm{As}_{2} \mathrm{~S}_{3}$ glass [27]. Considered the promising materials for fiber optics in the MIR range, numerous investigations of $\mathrm{ChG}$ glasses for fiber 
fabrication have been conducted over the past few decades, especially those based on S and Se [28-34]. Typical commercially available ChG fibers are mainly based on As-S and As-Se [35,36]. In addition, the systems that commonly used for ChG fibers in scientific research include Ge-As-Se [37-39], As-Se-Te [40-42] and Ga-La-S [43-45]. The three main kinds of fiber structures are the step-index fiber, MOF, and tapered fiber. This subsection introduces $\mathrm{ChG}$ fibers from these aspects.

\subsubsection{Step-Index Fibers}

A typical fiber structure is step-index geometry, which comprises a core with a high refractive index surrounded by a low index cladding. The core and cladding glasses chosen for ChG fiber fabrication must have good fiber-forming performances and similar thermal properties. Bulk ChGs are usually prepared using high-purity elements by melt-quenching $[46,47]$, as well as microwave radiation [48,49], or chemical vapor deposition techniques [50]. ChG fibers are usually made via the double crucible method [51-53], or pre-formed via rod-in-tube [54-56] or extrusion methods [57-59]. For years, extensive investigations on ChG glass purification and fiber drawing have been carried out by Russian researchers. The optical attenuations in fibers based on As-S, As-Se, and As-S-Se systems have been reduced to lower than $1 \mathrm{~dB} / \mathrm{m}$. In particular, $\mathrm{As}_{2} \mathrm{~S}_{3}$ multimode fibers have minimal losses: $0.012 \mathrm{~dB} / \mathrm{m}$ at $3.0 \mu \mathrm{m}$ and $0.014 \mathrm{~dB} / \mathrm{m}$ at $4.8 \mu \mathrm{m}$ [60]. In addition to low optical losses, ChG step-index fibers have advantages of high power handling and good flexibility and strength $[35,61]$.

The zero material dispersion wavelengths (ZMDW) of ChG glasses are always located at long wavelengths. For example, the $\mathrm{ZMDW}$ of $\mathrm{As}_{2} \mathrm{Se}_{3}$ glass is $\sim 8 \mu \mathrm{m}$, and that ${ }^{2} \mathrm{As}_{2} \mathrm{~S}_{3}$ is $5 \mu \mathrm{m}$ [62]. Depending partly on material dispersion, the ZDWs of ChG step-index fibers also lie in long wavelengths, resulting in a largely normal and steep dispersion in the relatively shorter wavelengths, which reduces the effective optical nonlinearity [63] and distorts the ultrashort optical pulses propagating in fibers [64]. Therefore, fiber dispersion must be carefully engineered with different waveguide dispersion for specific applications, such as the case of wavelength conversion and SC generation $[2,65]$. The dispersion properties can be calculated through Sellmeier equation [63]:

$$
n^{2}(\lambda)=1+\sum_{i} \frac{A_{i} \lambda^{2}}{\lambda^{2}-B_{i}^{2}}
$$

where $\lambda$ is the wavelength, and $A_{i}$ and $B_{i}$ are Sellmeier coefficients. To some extent, these nonlinear processes are also related to the nonlinear coefficient, $\gamma$, of ChG fibers, which is defined by [63]

$$
\gamma=\frac{2 \pi n_{2}}{\lambda A_{e f f}}
$$

where $A_{\text {eff }}$ is the effective mode area. Some typical values are $\gamma=100 \mathrm{~W}^{-1} \mathrm{~km}^{-1}$ for As-S fibers with $50 \mu \mathrm{m}^{2} A_{\text {eff }}$ [66], and $\gamma=2450 \mathrm{~W}^{-1} \mathrm{~km}^{-1}$ for As-Se fibers with $40 \mu \mathrm{m}^{2} A_{\text {eff }}$ [19]. These are both much greater than that of standard SMF 28 fiber $\left(\gamma=1 \mathrm{~W}^{-1} \mathrm{~km}^{-1}\right.$ with $\left.90 \mu \mathrm{m}^{2}\right)$ [67]. $\gamma$ can be dramatically improved by further decreasing the fiber's core diameter [68-70].

\subsubsection{MOFs}

MOFs have become a popular topic in recent years because of their unique optical properties, such as strong light confinement [33,71-73], adjustable dispersion [74-76], and enhanced optical nonlinearity $[2,77,78]$ when the core diameter and air holes are arranged along the transverse section of the fiber. As optical media with great fiber structure flexibility are designed to operate in the MIR, MOFs based on ChGs have already been reported extensively in the literature. Several typical geometrical profiles of ChG MOFs are shown in Figure 2. 


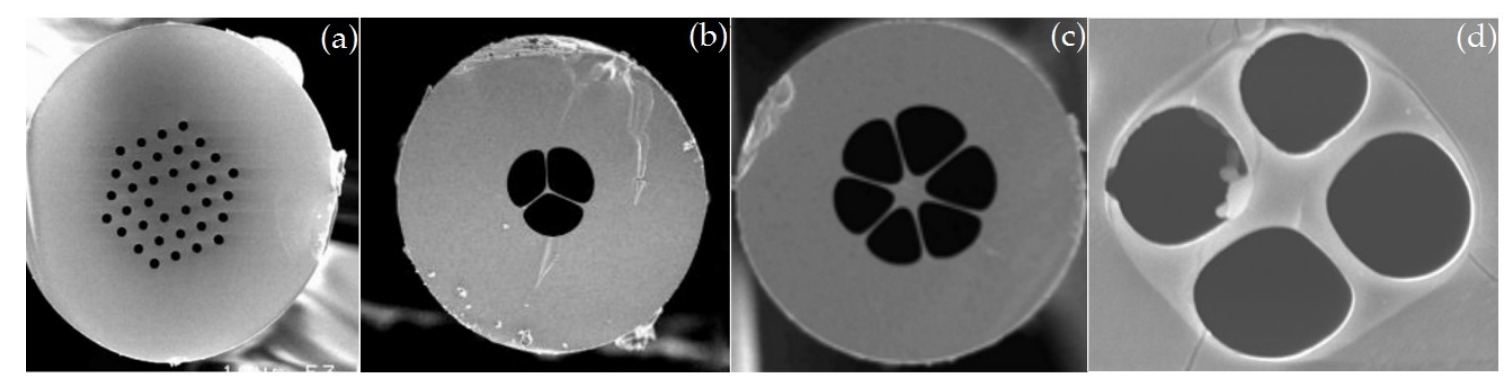

Figure 2. Geometrical profiles of ChG microstructured optical fibers (MOFs). (a) Photonic crystal fiber with regular hexagonal geometry and three air hole rings; (b) sSuspended-core fiber with three air holes; (c) suspended-core fiber with six air holes (from [79]); and (d) hybrid MOF (reproduced with permission from [80], copyright Optical Society of America, 2014).

The three research institutes mainly involved in the fabrication of ChG MOFs are the University of Rennes I, the University of Bourgogne, and Perfos Company. Apart from the extrusion technique, the other approaches that have been developed to fabricate ChG MOFs include stack and draw [81,82], casting $[72,83,84]$, and mechanical drilling $[33,85,86]$. The fabrication process of ChG MOFs is complicated and technically difficult. It has been shown that when the MOF core size is decreased, the fiber loss is increased due to microdeformations [87-89]. Nevertheless, a low loss of $<0.8 \mathrm{~dB} / \mathrm{m}$ in As-S MOF with a small core diameter of $3 \mu \mathrm{m}$ has been achieved [72].

Despite the long ZMDW of ChGs, large values of anomalous waveguide dispersion can be used to engineer the total dispersion into zero dispersion even in the anomalous regime [20]. MOFs have great advantages in terms of dispersion control because of their flexible design. ChG MOFs with ZDWs shorter than $2 \mu \mathrm{m}$ have been reported from experiments and simulations [33,90,91], and a very large $\gamma$ up to $4.9 \times 10^{4} \mathrm{~W}^{-1} \mathrm{~km}^{-1}$ was obtained from a $\mathrm{AsSe}_{2}-\mathrm{As}_{2} \mathrm{~S}_{5}$ hybrid MOF with a core diameter of $3.7 \mu \mathrm{m}[80]$.

\subsubsection{Tapered Fibers}

As a well-known post-processing technology, tapering fibers can also dramatically increase the optical nonlinearity and engineer the total dispersion of fibers. However, tapering is an easier technical task compared with MOFs in terms of fabrication difficulty. The typical methods used to taper ChG fibers include flame brushing [92] and electric heating [93], and a low tapering loss of $2 \mathrm{~dB}$ has been achieved [94]. The schematic of a typical ChG tapered fiber is shown in Figure 3.

During the tapering process, material dispersion is compensated by waveguide dispersion by reducing the fiber diameter, which results in the blue-shifting of ZDW. A small fiber core size corresponding to a large $\gamma$ of $1.85 \times 10^{5} \mathrm{~W}^{-1} \mathrm{~km}^{-1}$ has been reached in an As-Se fiber taper with a taper waist diameter of $0.47 \mu \mathrm{m}$ [95], a value that is approximately tens to hundreds of times than that of a ChG step-index fiber with a large mode area. By combining tapering with MOFs, a relatively greater nonlinearity can be obtained. Meanwhile, the threshold power required for nonlinear effects is relatively low. Self-phase modulation (SPM) can occur at a peak power lower than $1.5 \mathrm{~W}$ in a submicron $\mathrm{As}_{2} \mathrm{Se}_{3}$ taper [96].

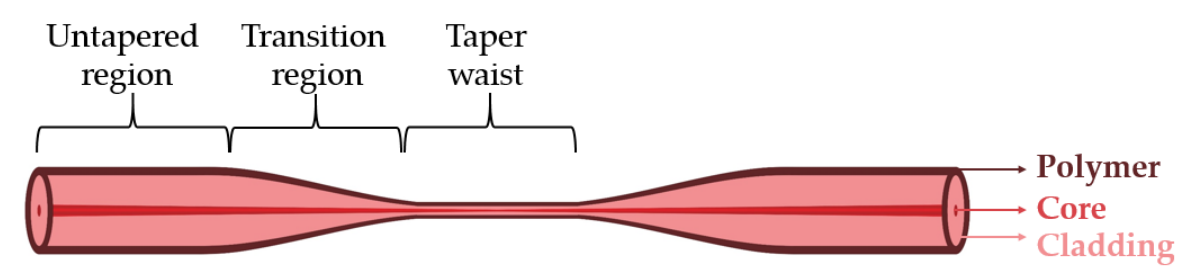

Figure 3. Schematic of a typical ChG tapered fiber. 


\section{MIR SC Generation in ChG Fibers}

MIR SC generation in ChG fibers has attracted wide attention since the first reported SC sources from an As-Se fiber in 2005 [97]. The MIR spectral region is particularly important because most molecules display fundamental vibration absorptions in this region. ChG glasses that exhibit excellent properties in this region have significant advantages over silica, tellurite and fluoride glasses, and are the unique media that can extend the SC spectrum to MIR or even to the far-infrared (FIR) region (longer than $10 \mu \mathrm{m}$ ).

SC sources from ChG fibers with a large bandwidth, high brightness, and high degree of coherence have recently become of great interest due to their potential applications in many fields. To date, the main research institutions engaged in MIR SC generation in ChG fibers are the Technical University of Denmark, the University of Laval, the Toyota Technological Institute, Ningbo University, and Mcgill University. Similar to Section 2.2, MIR SC generation in ChG fibers is reviewed in this chapter from the three aspects of fiber structure: SC generation in step-index fibers, MOFs, and tapered fibers.

\subsection{SC Generation in ChG Step-Index Fibers}

The study of SC generation in ChG step-index fibers started in 2005. Wei et al. [16] demonstrated SC generation using a 1.5-m-long $\mathrm{As}_{2} \mathrm{~S}_{3}$ single-mode step-index fiber pumped in the normal dispersion regime. A passively $1.5 \mu \mathrm{m}$ mode-locked Er-doped fiber laser with a pulse duration of $100 \mathrm{fs}$ at a repetition rate of $20 \mathrm{MHz}$ was used as the pump source. Using the maximum fiber-input power of $16.4 \mathrm{~mW}$, the output spectrum was broadened with a $-15 \mathrm{~dB}$ bandwidth of $310 \mathrm{~nm}$. Although the spectral width of the SC generation was not wide, the observed spectral broadening was very attractive, and it confirmed the potential for ChG fibers to be used for MIR SC generation. Highly nonlinear $\mathrm{ChG}$ fibers are therefore promising media for compact broadband MIR sources designed for different potential applications.

In the following years, some researchers reported SC generation in ChG step-index fibers which were excited by fiber lasers at short wavelengths [98-100]. However, broadband MIR SC generation was barely achieved in ChG step-index fibers pumped with a normal dispersion regime with a short pump wavelength from a fiber laser. This is because during the process of spectral extension in the normal dispersion regime, the nonlinear effects of SPM, optical wave break (OWB), and stimulated Raman Scattering (SRS) play important roles [63]. The SPM effect during the initial propagation in the fiber makes the broadened pump pulse spectra maintain almost symmetric shapes with typical oscillatory structures, which is induced by spectral interference at different temporal locations within the pulse where the same spectral components exist. Then, OWB occurs on the trailing and leading edges of the pulse, which is responsible for the additional broadening on both sides of the spectrum [20]. Moreover, the slightly asymmetric extension of the generated spectrum and the slightly increased energy of the relatively longer wavelengths are attributed to the SRS [16]. However, these nonlinear effects are limited by the pump peak power and dispersion slopes, inevitably impairing spectral broadening.

Generally, efficient and broadband SC generation can be obtained by pumping in the anomalous dispersion regime close to the ZDW of the fiber. In this case, SC generation in fibers is dominated by soliton dynamics, such as soliton fission and soliton self-frequency shift in the long wavelengths, and dispersion waves in the short wavelength [68,101-104]. First, the pump pulse transforms into a higher-order soliton, which shows periodic spectral and temporal evolution over a soliton period. Higher-order dispersion and SRS are the two most important effects that can perturb the ideal periodic evolution of the higher-order soliton and induce pulse breakup into multiple fundamental solitons through soliton fission. Then, each soliton experiences a continuous shift to longer wavelengths due to the Raman self-frequency shift [2]. Solitons that are ejected earlier from the input pulse have relatively shorter durations and faster propagation group velocities, leading to a greater frequency red-shift $[2,105]$. Under higher-order dispersion perturbing, solitons emit dispersion waves via the Cherenkov radiation at wavelengths that are phase-matched with solitons in the normal dispersion regime $[104,106]$. Finally, solitons trap the dispersion waves by group velocity matching, and cause 
them to shift to short wavelengths. Additional frequency components can also be generated by the cross-phase modulation and four wave mixing, and these effects can further broaden the spectral bandwidth of the achieved SC.

However, depending partly on the material dispersion, the ZDWs of ChG step-index fibers are usually located at long wavelengths $(>5 \mu \mathrm{m})$. Therefore, it is difficult to match the ZDWs of ChG fibers with the operation wavelengths of commercial fiber lasers. Moreover, the use of ChG step-index fibers in SC generation was limited by the lack of high peak power pump sources in the MIR until the discovery that optical parametric amplifiers (OPAs) and oscillators (OPOs) could be successful employed as MIR pump sources to excite fibers in the anomalous dispersion regime $[107,108]$.

An ultrabroad MIR SC, spanning from 1.4 to $13.3 \mu \mathrm{m}$, was generated experimentally when $\sim 100 \mathrm{fs}$ pulses with a central wavelength of $6.3 \mu \mathrm{m}$ and a repetition rate of $1 \mathrm{kHz}$ were launched into an 85-mm-long step-index fiber made of $\mathrm{As}_{2} \mathrm{Se}_{3}$ core and $\mathrm{Ge}_{10} \mathrm{As}_{23.4} \mathrm{Se}_{66.6}$ cladding. The pump peak power was estimated to be $2.29 \mathrm{MW}$, and the pump wavelength was located in the anomalous dispersion regime, just above the fiber ZDW of $5.83 \mu \mathrm{m}$ [105]. Figure 4 shows the setup used for SC generation and the measured SC result. This was the first time that an SC source with a spectral width of $>10 \mu \mathrm{m}$ had been achieved in ChG fibers, thus representing a breakthrough in broadband MIR light source research. The transparent atmospheric windows of 3-5 $\mu \mathrm{m}$ and $8-13 \mu \mathrm{m}$, and the significant part of the fingerprint region of molecular vibrational resonances were covered. Since then, the generation of broadband SC sources in ChG step-index fibers has made rapid development, driven by the large number of potential applications in MIR technology.

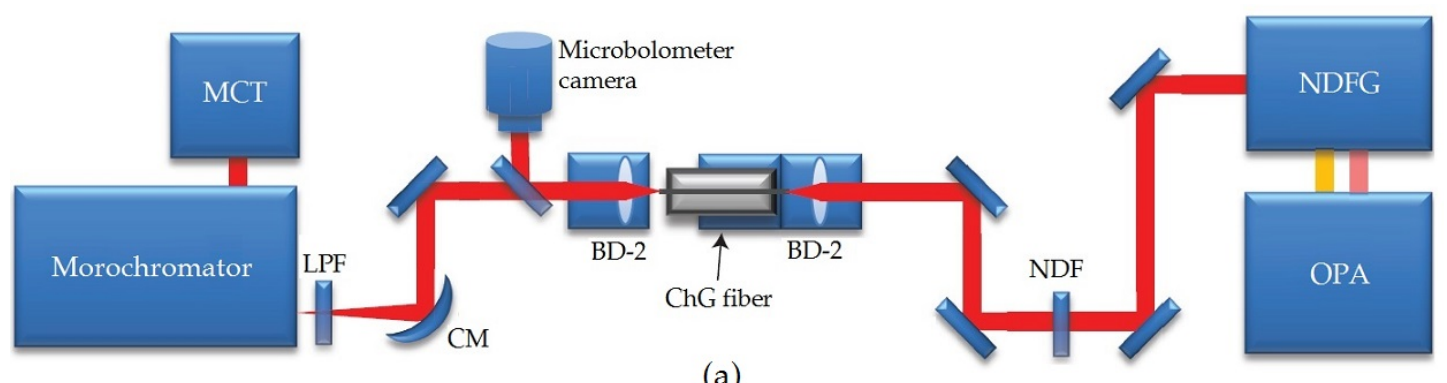

(a)

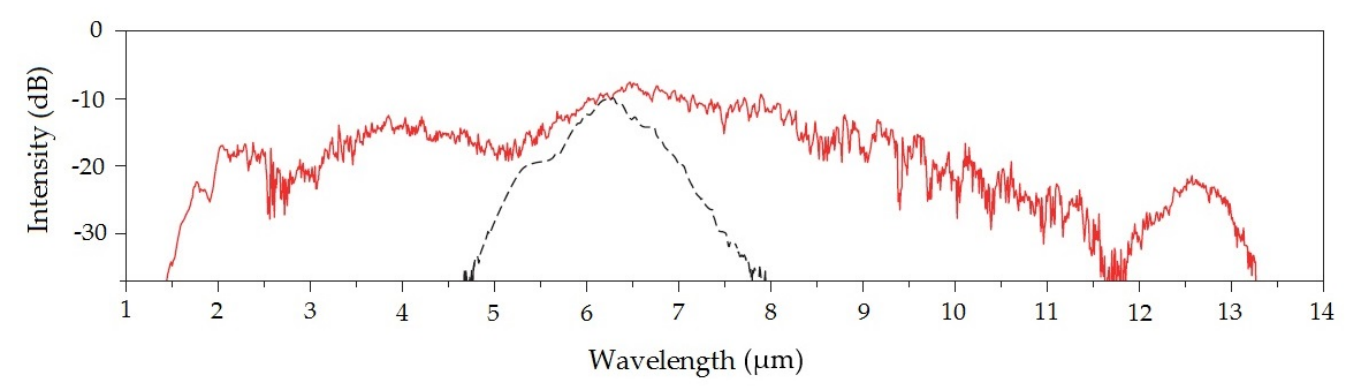

(b)

Figure 4. (a) Setup for supercontinuum (SC) generation in the ChG fiber. BD-2, black-diamond-2 aspheric lenses; CM, concave mirror; LPF, long-pass filter; MCT, mercury cadmium telluride; NDF, neutral density filter; NDFG, noncollinear difference frequency generation; OPA: optical parametric amplifier. (b) Measured SC generation in the ChG fiber pumped at $6.3 \mu \mathrm{m}$ (reproduced with permission from [105], copyright Springer Nature, 2014).

Researchers have subsequently focused on the enhancement of SC broadening. ChG fibers with short lengths, small core diameters, high nonlinearity, and optimized pump conditions have been designed and used to generate SC spectra with good performance [17,55,109-112]. For example, an As-Se fiber with a length of $3 \mathrm{~cm}$ and a ZDW of $5.5 \mu \mathrm{m}$ was pumped by pulses of $9.8 \mu \mathrm{m}$ with a pulse duration of $170 \mathrm{fs}$ and a repetition rate of $1 \mathrm{kHz}$, produced from a difference in frequency 
generation. When the peak power was $2.89 \mathrm{MW}$, the generation of SC spanning from 2 to $15.1 \mu \mathrm{m}$ was obtained [113].

Meanwhile, researchers started to explore novel glass systems of ChG fibers to achieve MIR SC. $\mathrm{Ou}$ et al. [114] reported the fabrication of a fiber with the core and cladding made of $\mathrm{Ge}_{15} \mathrm{Sb}_{25} \mathrm{Se}_{60}$ and $\mathrm{Ge}_{15} \mathrm{Sb}_{20} \mathrm{Se}_{65}$ glasses, respectively. An SC generation spanning from 1.8 to $14 \mu \mathrm{m}$ was achieved in a 20-cm-long fiber with a core diameter of $23 \mu \mathrm{m}$ by pumping at $6.0 \mu \mathrm{m}$ in the anomalous dispersion regime. The optical nonlinearity of the core glass $\left(19 \times 10^{-18} \mathrm{~m}^{2} / \mathrm{W}\right)$ was greater than that of $\mathrm{As}_{2} \mathrm{Se}_{3}$ because of the replacement of As by more the metallic $\mathrm{Sb}[110,115,116]$. Furthermore, $\mathrm{Ge}-\mathrm{Sb}-\mathrm{Se}$ glasses exhibit higher thermal and mechanical durability and have been demonstrated to be suitable for molded IR-transmitting lenses. The most important factor is that visible damage arises at a beam intensity of $3674 \mathrm{GW} / \mathrm{cm}^{2}$ for Ge-Sb-Se glass at $3.0 \mu \mathrm{m}$, a value more than twice than that for $\mathrm{As}_{2} \mathrm{Se}_{3}$ glass $\left(1524 \mathrm{GW} / \mathrm{cm}^{2}\right)$ [114]. This indicates that $\mathrm{Ge}-\mathrm{Sb}-\mathrm{Se}$ fibers can endure a relatively higher peak power. Such a large nonlinearity and a high laser-induced damage threshold of the glass gives $\mathrm{Ge}-\mathrm{Sb}-\mathrm{Se}$ fibers great potential to be used with an ultra-broad MIR SC with high output power. Similarly, a Ge-Sb-Se fiber with a core diameter of $6 \mu \mathrm{m}$ and length of $11 \mathrm{~cm}$ was pumped at $4.485 \mu \mathrm{m}$ with $330 \mathrm{fs}$ pulses, and an SC covering the $2-12 \mu \mathrm{m}$ spectral range with an output average power of $\sim 17 \mathrm{~mW}$ was achieved [117].

Te-based glasses have low phonon energies and high linear refractive indices, which results in wide optical windows and high nonlinear refractive indices [118-120]. Thus, relatively wider $\mathrm{SC}$ generation can be expected from Te-based fibers. However, the metallic characteristic of Te can lead to a greater tendency for crystallite formation, which may prevent the production of low-loss optical fibers due to scattering effects. A second consequence of the metallic characteristic of $\mathrm{Te}$ is a low bandgap that results in significant background carrier absorption caused at room temperature by thermally excited charge carriers. However, these drawbacks can be alleviated by substituting a small amount of Te with Se to lower the conductivity and dramatically increase the resistance to crystallization while retaining a wide optical window in the long wavelengths [115]. According to a previous report, Ge-As-Se-Te step-index fibers can be fabricated for long-wave transmissions as high as $12 \mu \mathrm{m}$ [121], but the optical fiber loss needs to be decreased to fit the requirements of SC generation and other applications. Zhao et al. [122] fabricated a fiber based on Ge-As-Se-Te with a transmission loss of $2-3 \mathrm{~dB} / \mathrm{m}$ in the $6.2-10.3 \mu \mathrm{m}$ wavelength range, and experimentally demonstrated MIR SC generation spanning from 1.5-14 $\mu \mathrm{m}$ when pumped by a $4.5 \mu \mathrm{m}$ laser with a pulse duration of $150 \mathrm{fs}$ and a repetition rate of $1 \mathrm{kHz}$. However, the broadening of SC spectra to the longer wavelengths was limited by the multiphoton absorption of Se-Se.

Previous work has demonstrated the potential of Ge-Ga-Te [120], Ge-Te-I [118], and Ge-Te-AgI [123,124] glass systems without Se for FIR applications. Iodine can trap free electrons from tellurium, helping to form more stable glass. Moreover, the high atomic weight of iodine, which is a neighbor of Te in the periodic table, allows the low phonon characteristics of the glass matrix to be maintained and the FIR transparency to be retained, while providing improved rheological properties. It has been shown that the nonlinearity of ChG glasses could be enhanced when doped with $\mathrm{Cu}$ or Ag [125]. A broad MIR SC spanning from 2.0 to $16.0 \mu \mathrm{m}$ (Figure 5) was successfully achieved when a Ge-Te-AgI fiber with double cladding and a minimal loss of $6 \mathrm{~dB} / \mathrm{m}$ at $11 \mu \mathrm{m}$ was pumped by OPA in the normal dispersion regime at $7 \mu \mathrm{m}$ [126]. This is the broadest MIR SC generation obtained experimentally in optical fibers. This demonstration has also revealed that SC spectra generated from Te-based ChG glass fibers can emit across the entire MIR molecular fingerprint region.

Table 2 lists the partial results of SC generation in ChG step-index fibers. It can be seen that the spectral bandwidths of SCs generated in ChG step-index fibers are limited when pumped with shorter laser pulses. In contrast, when fibers are pumped with pulses longer than $6.0 \mu \mathrm{m}$, the long wavelength edges of generated SCs can be extended to $>12 \mu \mathrm{m}$. In addition, wider SC spectrums can be obtained in ChG fibers with higher refractive indexes. It is worth noting that the maximum average power of a generated SC is generally low, limited to the order of $\mathrm{mW}$, or even $\mu \mathrm{W}$, due to the low pump 
repetition rate [105]. However, SC sources require not only wide bandwidths but also high brightness for practical applications. The output power of generated SCs from ChG fibers is usually limited by the average power of the input pump pulse, and altering the pump source parameters can scale up the input average and further increase the output power. Two common approaches can be used for power scaling: increasing the repetition rate while maintaining pulse duration and peak power, and increasing the pulse duration while maintaining the other parameters. For the first approach, an output power of $550 \mathrm{~mW}$ can be achieved in a 23-cm-long ChG fiber pumped by OPO and OPA systems with a pulse duration of $\sim 450 \mathrm{fs}$ and, notably, a high repetition rate of $42 \mathrm{MHz}$ [127]. Similarly, by pumping a 11-cm-long fiber with $330 \mathrm{fs}$ pulses at a repetition rate of $21 \mathrm{MHz}$ from OPA, a high brightness of $17 \mathrm{~mW}$ for the generated SC was achieved [117]. For the second approach, in a 3-m-long ChG fiber pumped with a relatively low repetition rate of $100 \mathrm{kHz}$, a large output power of $143 \mathrm{~mW}$ was also obtained due to the long pulse duration of $1 \mathrm{~ns}$ [128]. Furthermore, the highest ever reported SC output power of $565 \mathrm{~mW}$ from a 2-m-long ChG fiber resulted from pump pulses combined with a long pulse duration and large repetition rate, of $40 \mathrm{ps}$ and $10 \mathrm{MHz}$, respectively [99].

When the pump conditions are given and unable to be changed, ChG fibers with a large cores, which can relax the focusing of the OPA beam can be adopted to increase the coupling efficiency and improve the output power [117]. The two other ways to achieve a high output power are by reducing the fiber loss resulting from the impurity band and by shortening fiber length used for SC generation $[129,130]$.

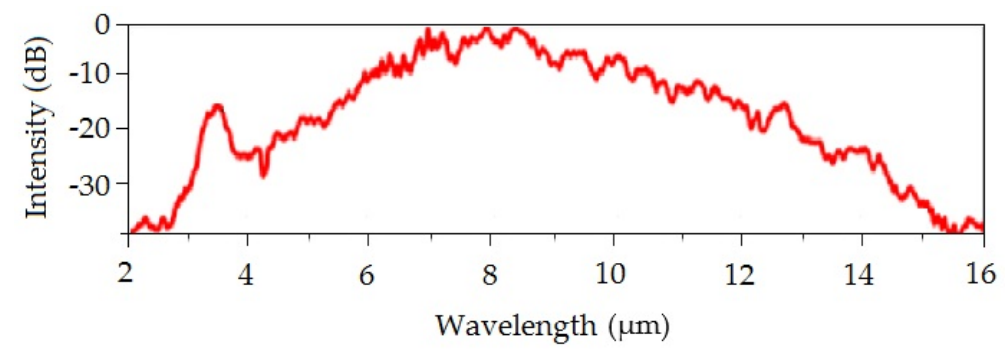

Figure 5. MIR SC spanning from 2.0 to $16.0 \mu \mathrm{m}$, generated in a Ge-Te-AgI fiber when pumped at $7 \mu \mathrm{m}$ (reproduced with permission from [126], copyright John Wiley and Sons, 2017).

Table 2. Partial results of supercontinuum (SC) generation in ChG step-index fibers.

\begin{tabular}{cccccc}
\hline Fiber & Fiber Length & $\begin{array}{c}\text { Pump Wavelength/Pulse } \\
\text { Width/Repetition }\end{array}$ & SC Bandwidth & Output Power & Year \\
\hline $\mathrm{As}_{2} \mathrm{~S}_{3}$ & $2 \mathrm{~m}$ & $2.45 \mu \mathrm{m} / 40 \mathrm{ps} / 10 \mathrm{MHz}$ & $1.9-4.8 \mu \mathrm{m}$ & $565 \mathrm{~mW}$ & $2012[99]$ \\
$\mathrm{As}_{2} \mathrm{Se}_{3}$ & $8.5 \mathrm{~cm}$ & $6.3 \mu \mathrm{m} / 100 \mathrm{fs} / 1 \mathrm{kHz}$ & $1.4-13.3 \mu \mathrm{m}$ & $150 \mu \mathrm{W}$ & $2014[105]$ \\
$\mathrm{Ge}_{12} \mathrm{As}_{24} \mathrm{Se}_{64}$ & $11 \mathrm{~cm}$ & $4.0 \mu \mathrm{m} / 330 \mathrm{fs} / 21 \mathrm{MHz}$ & $1.8-10 \mu \mathrm{m}$ & $1.26 \mathrm{~mW}$ & $2015[110]$ \\
$\mathrm{Ge}_{11.5} \mathrm{As}_{24} \mathrm{Se}_{64.5}$ & $13.5 \mathrm{~cm}$ & $4.1 \mu \mathrm{m} / 320 \mathrm{fs} / 10.5 \mathrm{MHz}$ & $1.8-9.8 \mu \mathrm{m}$ & $3 \mathrm{~mW}$ & $2015[55]$ \\
$\mathrm{As}_{2} \mathrm{~S}_{3}$ & $23 \mathrm{~cm}$ & $3.83 \mu \mathrm{m} / 450 \mathrm{fs} / 42 \mathrm{MHz}$ & $3.0-4.8 \mu \mathrm{m}$ & $550 \mathrm{~mW}$ & $2015[127]$ \\
$\mathrm{As}_{2} \mathrm{Se}_{3}$ & $3 \mathrm{~cm}$ & $9.8 \mu \mathrm{m} / 170 \mathrm{fs} / 1 \mathrm{kHz}$ & $2.0-15.1 \mu \mathrm{m}$ & - & $2016[113]$ \\
$\mathrm{Ge}_{15} \mathrm{Sb}_{15} \mathrm{Se}_{70}$ & $11 \mathrm{~cm}$ & $4.485 \mu \mathrm{m} / 330 \mathrm{fs} / 21 \mathrm{MHz}$ & $2.2-12 \mu \mathrm{m}$ & $17 \mathrm{~mW}$ & $2016[117]$ \\
$\mathrm{As}_{2} \mathrm{~S}_{3}$ & $3 \mathrm{~m}$ & $2.19 \mu \mathrm{m} / 1 \mathrm{~ns} / 100 \mathrm{kHz}$ & $2.0-4.0 \mu \mathrm{m}$ & $143 \mathrm{~mW}$ & $2016[128]$ \\
$\mathrm{As}_{2} \mathrm{Se}_{3}$ & $12 \mathrm{~cm}$ & $6.5 \mu \mathrm{m} / 150 \mathrm{fs} / 1 \mathrm{kHz}$ & $2.0-12.7 \mu \mathrm{m}$ & $300 \mu \mathrm{W}$ & $2017[129]$ \\
$\left(\mathrm{Ge}_{10} \mathrm{Te}_{43}\right)_{90}-(\mathrm{AgI})_{10}$ & $14 \mathrm{~cm}$ & $7.0 \mu \mathrm{m} / 150 \mathrm{fs} / 1 \mathrm{kHz}$ & $2.0-16 \mu \mathrm{m}$ & - & $2017[126]$ \\
\hline
\end{tabular}

\subsection{SC Generation in ChG MOF Fibers}

The ability to tailor the fiber dispersion profile to the particular needs of its intended application is an underlying theme across all glass and fiber designs. The use of MOF technology provides primary flexibility in dispersion control to match the conditions of the pump source. By changing the structural parameters, the waveguide dispersion of MOFs can be controlled, so that the total dispersion can be engineered precisely. A key geometrical parameter of MOFs is the ratio of fiber core diameter (d) and the pitch $(\Lambda)$, which can control the waveguide dispersion over a wide wavelength range, as shown in Figure 6. 


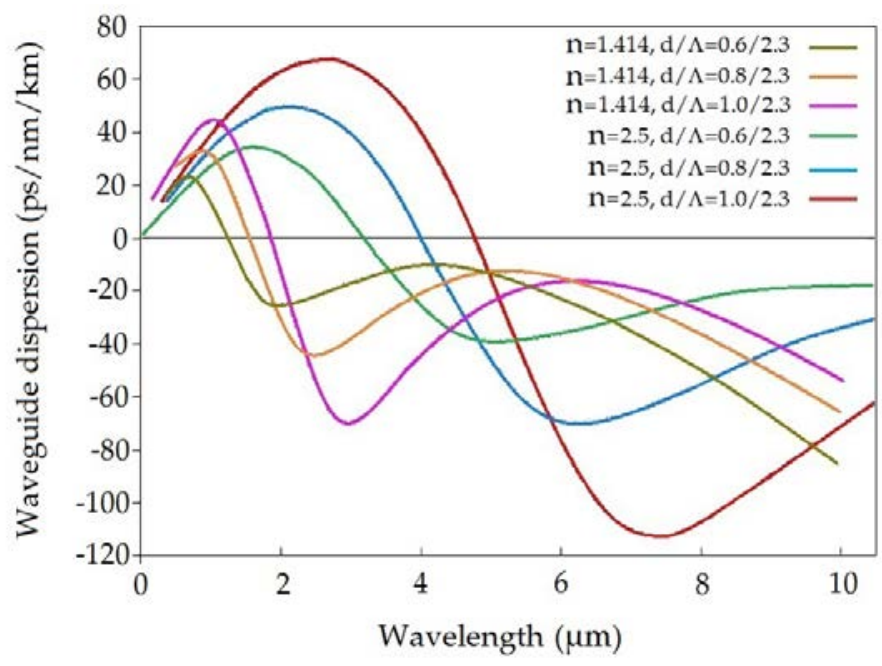

Figure 6. Calculated waveguide dispersion as a function of the wavelength for MOFs with three different $d / \Lambda$ ratios for $n=1.444$ and $n=2.5$, where $\mathrm{n}$ is the linear refractive index of the glass matrix (reproduced with permission from [131], copyright Taylor \& Francis, 2009).

The first ChG MOF, made in 2000 by Monro et al., was obtained by extrusion and made of only one ring of holes with an irregular structure, but no light propagation was demonstrated [132]. In 2005, Shaw et al. [97] fabricated an As-Se photonic crystal fiber (PCF) with a core diameter of $10 \mu \mathrm{m}$, and the ZDW of this fiber was estimated to be $\sim 6 \mu \mathrm{m}$. SC generation extending from 2.1 to $3.2 \mu \mathrm{m}$ was achieved in a 1-m-long fiber pumped with $100 \mathrm{fs}$ pulses from an OPA at $2.5 \mu \mathrm{m}$. Notably, the dispersion of the fiber and pump wavelength did not match well in this demonstration.

Subsequently, the ChG MOFs used for MIR SC generation were mainly based on suspended-core fibers (SCFs). An $\mathrm{As}_{2} \mathrm{~S}_{3} \mathrm{SCF}$ with a core diameter of $2.6 \mu \mathrm{m}$, fabricated by El-Amraoui et al. [33], had a ZDW of $2.2 \mu \mathrm{m}$, appearing strongly shifted toward shorter wavelengths in comparison to the ZDW of bulk glass and showing the influence of the geometry, and particular the core diameter, on optical properties. When a $400 \mathrm{fs}$ beam was injected at $1557 \mathrm{~nm}$ with a repetition rate of $16.75 \mathrm{MHz}$ and a peak power of $5.6 \mathrm{~kW}$ into a $68-\mathrm{cm}-$ long $\mathrm{As}_{2} \mathrm{~S}_{3} \mathrm{MOF}$, a broadening spectrum spanning from 1 to $2.6 \mu \mathrm{m}$ was obtained.

To ensure efficient SC generation, researchers have chosen suitable pump wavelengths to excite MOFs in the anomalous dispersion regime. Møller et al. [133] presented SC generation in an 18-cm-long $\mathrm{As}_{38} \mathrm{Se}_{62} \mathrm{SCF}$ with a core diameter of $4.5 \mu \mathrm{m}$ and $\mathrm{ZDW}$ of $3.5 \mu \mathrm{m}$ pumped at different wavelengths with $320 \mathrm{fs}$ pulses from an OPA. When the pump wavelength was shifted from 3.5 to $4.7 \mu \mathrm{m}$, the solitonic long wavelength edge moved to longer wavelengths in the simulated spectra, and accordingly, the dispersive waves were shifted to shorter wavelengths. Consequently, the broadest numerical spectrum, spanning from 1.65 to $7.7 \mu \mathrm{m}$, and the largest experimental output power of $15.6 \mathrm{~mW}$ were obtained in this work.

In SCFs, dispersion profile optimization can be accomplished by changing the structural parameters, such as the fiber core diameter $(d)$ and the bridge width $(w)[90,91,134,135]$. As can be seen from Figure 7, the calculated ZDWs of SCFs can be shifted to shorter wavelengths by reducing $d$ and $w$ to match the pump wavelength. For example, the SCF fiber geometry was carefully designed by Mouawad et al. [86] in 2014 to allow efficient pumping by an OPO delivering $200 \mathrm{fs}$ pulses at $2.5 \mu \mathrm{m}$, which was close to the ZDW in the anomalous dispersion regime. The $\mathrm{As}_{2} \mathrm{~S}_{3} \mathrm{SCF}$ fiber had an outer diameter of $130 \mu \mathrm{m}$ and three holes centered on a central solid core with a diameter of $3.4 \mu \mathrm{m}$, exhibiting a ZDW close to $2.4 \mu \mathrm{m}$ and a $\gamma$ of $1150 \mathrm{~W}^{-1} \mathrm{~km}^{-1}$. At a peak pump power of $4.86 \mathrm{~kW}$, this fiber was clearly pumped in the anomalous dispersion regime and was characterized by a strong, rapid SPM process followed by soliton fission. The resulting spectrum extended from 600 to $4100 \mathrm{~nm}$ in the $-40 \mathrm{~dB}$ range. 


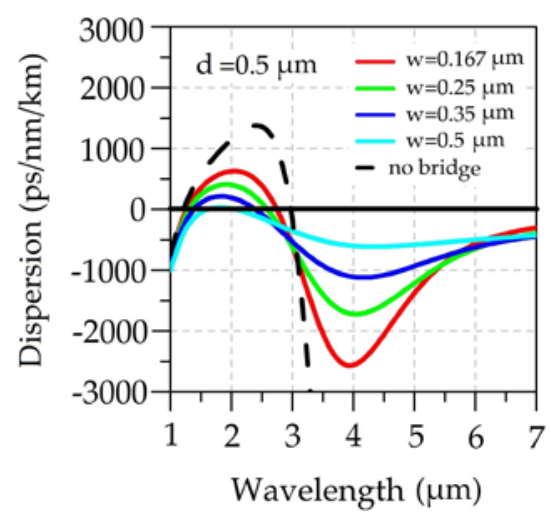

(a)

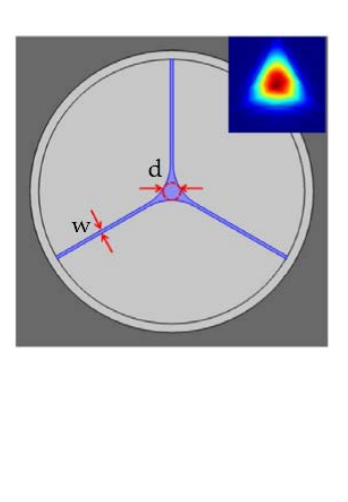

(b)

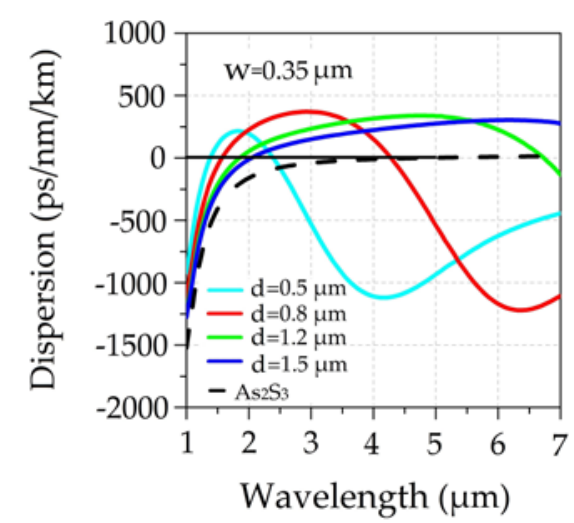

(c)

Figure 7. (a) Cross-section of a ChG SCF with three bridges; $d$ is the fiber core diameter; $w$ is the bridge width. (b) Dispersion profiles versus the wavelength for suspended-core fibers (SCF) with a bridge width of $0.35 \mu \mathrm{m}$ and different values of $\mathrm{d}$; and (c) dispersion profiles versus the wavelength for SCF with a fiber core diameter of $0.5 \mu \mathrm{m}$ and different values of $\mathrm{w}$.

Several researchers have reported wide SC generation in ChG-silica waveguides [136-138]. To more precisely engineer the dispersion profile, hybrid MOFs fabricated by two materials for the core and cladding glasses were proposed and studied theoretically and experimentally [139-141], and the adjustability of these can greatly facilitate effective SC generation. Recently, Cheng et al. [80] fabricated a hybrid four-hole $\mathrm{AsSe}_{2}-\mathrm{As}_{2} \mathrm{~S}_{5} \mathrm{MOF}$ with a large refractive index difference with a ZDW of $3380 \mathrm{~nm}$ and $\gamma$ of $4.9 \times 10^{4} \mathrm{~W}^{-1} \mathrm{~km}^{-1}$, and they obtained a 1.25-5.4 $\mu \mathrm{m}$ SC source pumped at $3389 \mathrm{~nm}$. The introduced $\mathrm{As}_{2} \mathrm{~S}_{5}$ cladding exhibits better transmission properties compared with those of $\mathrm{As}_{2} \mathrm{~S}_{3}$ glass in the visible and IR range. Subsequently, Cheng et al. [142] designed a hybrid MOF made of a ChG core and a tellurite cladding, and the ZDW of this fiber was downshifted to $2370 \mathrm{~nm}$. By pumping at $2600 \mathrm{~nm}$ in the anomalous dispersion regime, flattened SC generation spanning from $\sim 950$ to $3350 \mathrm{~nm}$ was experimentally realized. Besides tellurite glasses, borosilicate glasses have also been used as cladding materials of MOFs. Salem et al. [143] numerically reported MIR SC generation from 1 to $5 \mu \mathrm{m}$ in an $\mathrm{As}_{2} \mathrm{~S}_{5}$-borosilicate MOF.

It has been shown that fiber loss increases due to microdeformations when the core size of MOF is decreased [72]. The output SC spectrum bandwidth is critically correlated with MOF attenuation, especially regarding dramatic absorption peaks. Savelii et al. [144] experimentally demonstrated SC generation spanning from 1.2 to $3.2 \mu \mathrm{m}$ in a 45-mm-long $\mathrm{As}_{2} \mathrm{~S}_{3}$ SCF with a core diameter of $3.2 \mu \mathrm{m}$ when pumped at $2.3 \mu \mathrm{m}$ with a peak power of $4.6 \mathrm{~kW}$. However, the SC generation could be extended to $5.5 \mu \mathrm{m}$ when the extra losses of absorption peaks were neglected in the numerical simulation. The extra losses induced by $\mathrm{OH}$ - and $\mathrm{SH}$ - groups confirmed the dramatic limitation of the SC broadening process.

Additionally, the design of MOFs with air holes implies that the fiber core can be in contact with the ambient atmosphere. Therefore, MOFs are more exposed to the external environment compared with step-index fibers. Indeed, it has already been shown in silica MOFs that exposure to air impacts fiber transmission by an increase of the $\mathrm{OH}^{-}$absorption band at $1.4 \mu \mathrm{m}$ [145]. SC generation was demonstrated by Mouawad et al. [85] in a 25-mm-long, 7-month aged counterpart $\mathrm{As}_{2} \mathrm{~S}_{3} \mathrm{SCF}$ with a ZDW of $2.65 \mu \mathrm{m}$. A multistage OPA was used as the pump source, which delivered $300 \mathrm{fs}$ pulses with a repetition rate of $43 \mathrm{MHz}$. When the average pump power was fixed at $190 \mathrm{~mW}$ with different wavelengths, the SC spectral bandwidth covered less than $1200 \mathrm{~nm}$, which was obviously narrower than that of the fresh fiber which spanned almost $2000 \mathrm{~nm}$ (Figure 8), confirming that the typical nonlinear broadening process in the MOF can be influenced by deleterious aging phenomena. Extra losses induced by the exposure period can reduce the transmission efficiency in aged MOF, and a certain beam power is inevitably consumed during propagation $[84,146,147]$. 


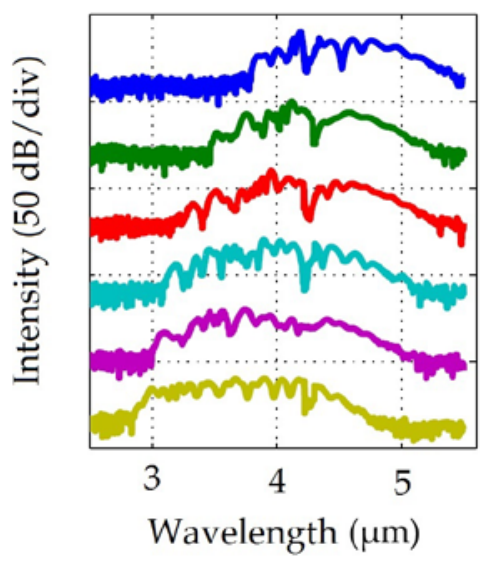

(a)

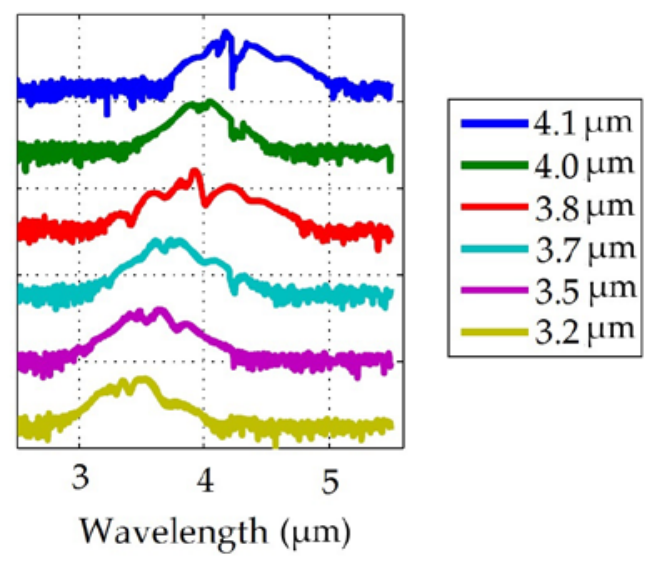

(b)

Figure 8. Measured SC generation in 25-mm-long fresh (a) and 7-month aged (b) $\mathrm{As}_{2} \mathrm{~S}_{3}$ fiber pumped with various wavelengths at average power of $190 \mathrm{~mW}$ (reproduced with permission from [85], copyright Springer Nature, 2016).

From the above discussions, it is clear that ChG MOFs have the advantages of a wide dispersion adjustable range and a large $\gamma$, but the generated SC spectra are not as wide as those from step-index fibers due to the low power coupling efficiency. In addition, the impact of optical aging in MOFs on SC generation needs to be considered for long-term applications in non-controlled atmospheric conditions [146].

\subsection{SC Generation in ChG Tapered Fibers}

Another important method for tailoring the dispersion property is the tapering of fibers, which can engineer the overall dispersion from normal to zero or even into the anomalous region and enable a dramatic increase in nonlinearity by reducing the effective mode area. Using a ChG tapered fiber with an $\mathrm{As}_{2} \mathrm{Se}_{3}$ core and $\mathrm{As}_{2} \mathrm{~S}_{3}$ cladding as an example, the dispersion, $\gamma$, and $\mathrm{A}_{\text {eff }}$ as a function of the fiber core diameter are shown in Figure 9. Owing to the improvement of fiber fabrication and tapering techniques, ChG tapered fibers have been used in many applications, such as frequency conversion, chemical sensing, and SC generation. In particular, by using tapered fibers, the pump power required for SC generation can be decreased, and the pump wavelength can be shortened.

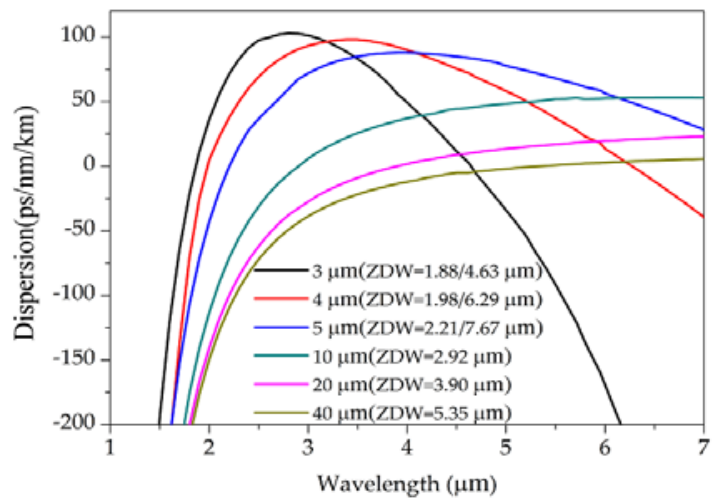

(a)

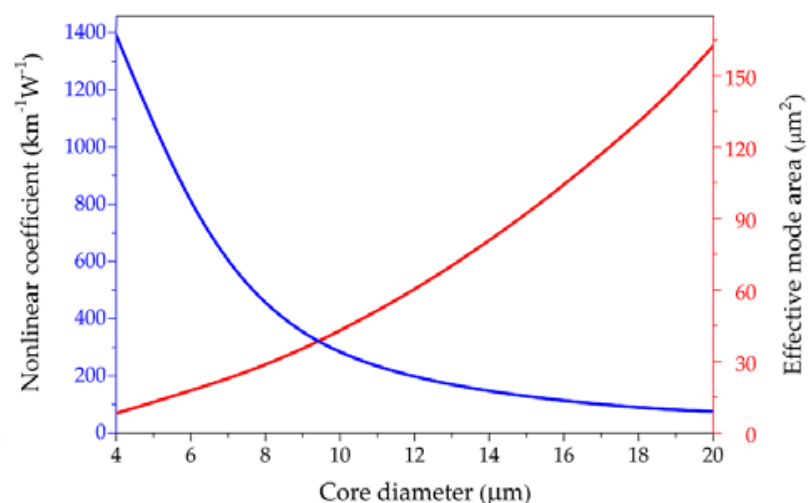

(b)

Figure 9. Dispersion (a), nonlinear coefficient $(\gamma)$, and effective mode area $\left(\mathrm{A}_{\mathrm{eff}}\right)(\mathbf{b})$ of a ChG tapered fiber with an $\mathrm{As}_{2} \mathrm{Se}_{3}$ core and $\mathrm{As}_{2} \mathrm{~S}_{3}$ cladding as a function of the fiber's core diameter.

The use of ChG tapered fibers for SC generation was first demonstrated in 2007 by Mägi et al. [70]. $\mathrm{An} \mathrm{As}_{2} \mathrm{Se}_{3} \mathrm{ChG}$ fiber with a cladding diameter of $165 \mu \mathrm{m}$ was tapered down to a waist diameter 
of $1.2 \mu \mathrm{m}$ with a nonlinear coefficient $(\gamma)$ of $68,000 \mathrm{~W}^{-1} \mathrm{~km}^{-1}$, which was 62,000 times larger than that of standard single-mode silica fibers. A mode-locked fiber laser with a pulse duration of $1.48 \mathrm{ps}$, repetition rate of $4 \mathrm{MHz}$, and wavelength of $1545 \mathrm{~nm}$ was used as the pump source to excite the tapered fiber. The pump pulses were extended at the pump peak power of $5.69 \mathrm{~W}$ by the nonlinear process of SPM. Given the longer dispersion length compared with the length of the sample, the dispersion did not significantly contribute to the spectral broadening. In 2011, Hudson at al. [68] increased the $\gamma$ to $12,400 \mathrm{~W}^{-1} \mathrm{~km}^{-1}$ in an $\mathrm{As}_{2} \mathrm{~S}_{3}$ tapered fiber with a taper waist diameter of $1.3 \mu \mathrm{m}$ and a mode area of $0.8 \mu \mathrm{m}^{2}$, exhibiting a ZDW around $1.4 \mu \mathrm{m}$. Pump pulses with a duration of $250 \mathrm{fs}$ and a repetition frequency of $38.6 \mathrm{MHz}$ were generated from an Er-fiber-based, mode-locked laser. By carefully tailoring the input pulse chirp and utilizing the robust power handing capabilities, a $-20 \mathrm{~dB}$ bandwidth spanning from 970 to $1990 \mathrm{~nm}$ was achieved from the fiber taper using a pump pulse energy of only $77 \mathrm{pJ}$ ( $3 \mathrm{~mW}$ average power). Rudy et al. [148] adopted a Tm-doped fiber laser and amplifier system as the pump source, which produced sub-100-fs pulses with a center wavelength of $2.04 \mu \mathrm{m}$ at a repetition rate of $75 \mathrm{MHz}$. An $\mathrm{As}_{2} \mathrm{~S}_{3}$ single mode fiber with a core/cladding diameter of $7 / 160 \mu \mathrm{m}$ was tapered to a diameter of $2 \mu \mathrm{m}$ using the in situ tapering method to shift the dispersion to the anomalous region. A $~ 1$ to $3.7 \mu \mathrm{m}$ SC was obtained from this tapered fiber at a pulse energy of $300 \mathrm{pJ}$.

OPA has also been used as a pump source to excite ChG tapered fibers to broaden SCs to longer wavelengths. Sun et al. [34] fabricated an $\mathrm{As}_{2} \mathrm{Se}_{3}-\mathrm{As}_{2} \mathrm{~S}_{3}$ fiber with high numerical aperture (NA) of 1.45. A 15-cm-long tapered fiber with a core diameter at the taper waist of $1.9 \mu \mathrm{m}$ was prepared for SC generation. This tapered fiber exhibited a ZDW of $3.3 \mu \mathrm{m}$ and a low anomalous dispersion at longer wavelengths. When pumped by pulses from an OPA with a pulse duration of $100 \mathrm{fs}$ and a peak power of $500 \mathrm{~kW}$ at $3.4 \mu \mathrm{m}$, the generated SC in this tapered fiber had a $20 \mathrm{~dB}$ spectrum covering from 1.5 to longer than $4.8 \mu \mathrm{m}$ (limited by the measurement range of the spectrometer).

Many researchers have attempted to extend the spectrum into the MIR region and increase the output power from ChG tapered fibers. However, the long wavelength edges of SCs obtained in ChG tapered fibers have been limited to $5 \mu \mathrm{m}$, with output powers lower than $15 \mathrm{~mW}$. This phenomenon can be attributed not only to the low input power, but also to the energy loss in the transition region of the tapered fiber due to the decrease in fiber size.

Apart from increasing pump power, enhancing nonlinearity and reducing power consumption in higher-order modes of fibers, both are effective methods to broaden SC bandwidth and improve the output power in ChG tapered fibers. Tapered MOFs with large-mode areas can also be used for SC generation; thus, a high coupling efficiency and damage threshold for the pump power injected to the fiber end facet will be obtained, while the tapered waist offers strong nonlinearity and anomalous dispersion at the pump wavelength. Moreover, the MOF structure can ensure single-mode propagation, which improves the beam quality and reduces losses in the taper due to higher-order mode stripping. Peterson et al. [149] tapered a $15.1 \mu \mathrm{m}$ core $\mathrm{Ge}_{10} \mathrm{As}_{22} \mathrm{Se}_{68} \mathrm{PCF}$ with a large mode area into a core diameter of $5.9 \mu \mathrm{m}$ at the taper waist. The higher-order modes excited in the large-core fiber were stripped during propagation in the transition region. By using an OPA source with a pulse duration of $250 \mathrm{fs}$ and a repetition rate of $21 \mathrm{MHz}$ at $4 \mu \mathrm{m}$, the broadest bandwidth (from 1 to $11.5 \mu \mathrm{m}$ ) was obtained with an average output power of $35.4 \mathrm{~mW}$, and the maximum output power of $57.3 \mathrm{~mW}$ had a spectral bandwidth spanning from 1 to $8 \mu \mathrm{m}$ in the tapered PCFs. Several improvements were also derived to guide future optimization of tapered fibers. Relatively shorter taper waists, a higher pitch-to-hole ratio, and shorter fiber lengths before the taper are all advantageous for extending SC to longer wavelengths.

Furthermore, other structural parameters of tapered fibers, such as taper waist diameter and transition region length can affect the SC results. Some researchers have demonstrated that wider SC generation can be achieved in a tapered fiber with a smaller diameter [150-152]. A small fiber diameter produces a small $A_{\text {eff }}$ in ChG tapered fibers, which increases the laser power intensity at the taper waist. Nonlinear power intensity dependent effects, such as SPM and SRS, are significant, and can lead to wide SC generation. However, broadband SC generation from the tapered fiber is often obtained at 
the cost of low output power. The effects of the transition region length of an As-S tapered fiber on SC spectral behavior were investigated by Wang et al. [153]. As shown by the experimental results in Figure 10, when the diameter of the transition region changes slowly with a relatively longer transition length, this is always accompanied by a lower number of higher-order modes, and thus, a higher transmission efficiency of light, resulting in a higher output power and a larger spectral broadening from the tapered fiber. SC generation spanning 1.4-7.2 $\mu \mathrm{m}$ with an average power of $1.06 \mathrm{~mW}$ was achieved from a 12-cm-long, As-S tapered fiber with a transition region length of $10 \mathrm{~mm}$, pumped by an OPA with a pulse duration of $150 \mathrm{fs}$ and a repetition rate of $1 \mathrm{kHz}$ at $3.25 \mu \mathrm{m}$.

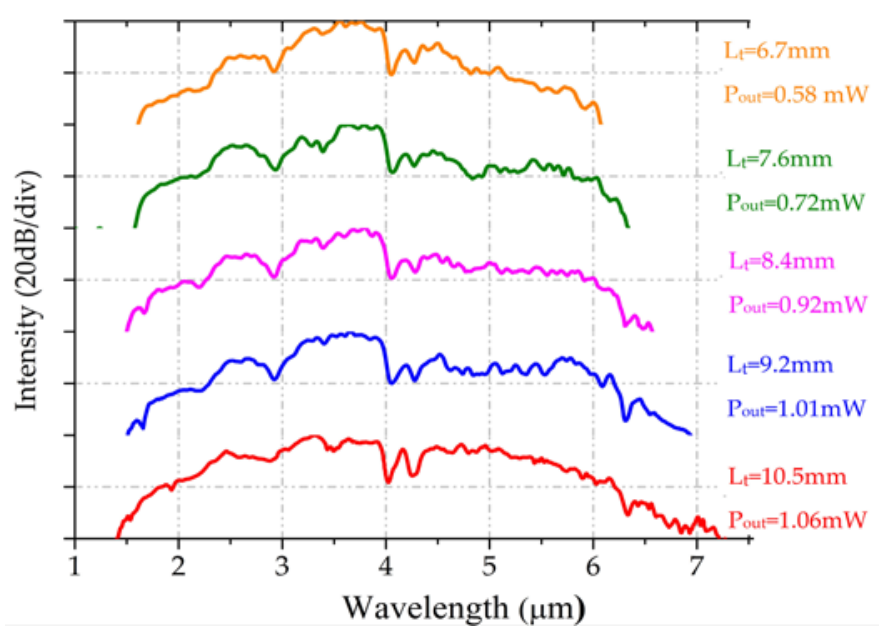

Figure 10. Measured SC spectra generated from 12-cm-long As-S ChG tapered fibers with transition region lengths varying from 6.7 to $10.5 \mathrm{~mm}$, pumped at $3.25 \mu \mathrm{m}$.

Owing to the requirements of dispersion control and nonlinearity, fibers are usually tapered down to extremely small diameters of a few micrometers or even submicrons $[96,151]$. This phenomenon results in the very low mechanical strength of tapered fibers during preparation, optical testing, and practical applications. To overcome this obstacle, polymer jackets with large diameters have been used to coat ChG fibers for convenient handling. The commonly used polymers are PMMA [69,95], PES [61,151], and PEI [151], which are thermally compatible with ChG fibers and can be tapered without removal. Unlike bare-glass-fiber tapering [154], the polymer jacket facilitates fiber drawing and helps avoid oxidation to reduce the aging of ChG fibers. Apart from improving a tapered fiber's mechanical strength, the polymer jacket can also provide dispersion engineering, as reported in the literature [69].

\section{Coherent SC Sources Based on ChG Fibers}

Many significant applications of SC sources require both an extraordinary bandwidth and a high average power as well as specific coherence properties. For instance, optical coherence tomography requires low coherence [155]. Meanwhile, applications in laser synchronization, frequency metrology and nonlinear microscopy require extremely high coherence [156-158]. Therefore, coherent MIR SC sources have attracted much attention because of their numerous application prospects.

To quantitatively study the coherence degradation, the modulus of the complex degree of coherence is determined from the following equation $[2,159]$ :

$$
\left|g_{12}^{(1)}\left(\lambda, t_{1}-t_{2}\right)\right|=\left|\frac{\left\langle E_{1}^{*}\left(\lambda, t_{1}\right) E_{2}^{*}\left(\lambda, t_{2}\right)\right\rangle}{\sqrt{\left\langle\left|E_{1}\left(\lambda, t_{1}\right)\right|^{2}\left|E_{2}\left(\lambda, t_{2}\right)\right|^{2}\right\rangle}}\right|,
$$


where $E$ is the intensity of the electric field. The angular brackets represent an ensemble average over independently generated pairs of SC spectra, and $t$ is the time measured on the resolution time scale of the spectrometer used to resolve these spectra. The modulus, $\left|g_{12}^{(1)}\right|$, at $t_{1}-t_{2}=0$ can be adopted in situations only concerning the wavelength dependence of the coherence. It is worth nothing that $\left|g_{12}^{(1)}\right|$, a measure of the phase stability of two fields in the interval [0:1], is calculated over a finite bandwidth at each wavelength of the spectra. As expected, $\left|g_{12}^{(1)}\right|=1$ over the entire bandwidth corresponds to perfect coherence, whereas $\left|g_{12}^{(1)}\right|=0$ implies that the two spectral phases are completely irrelevant.

The coherence property of MIR SC light depends on the parameters of pump light and the nonlinear processes involved in the spectral broadening mechanism [2,159-161]. For the pump scheme, a laser light with short pulse width and high stability is necessary to reduce the coherence degradation caused by technical noise [2]. For the spectral broadening mechanism, the coherence degradation of SC sources is mainly caused by noise amplification which comes from SRS and modulation instability $[162,163]$.

In most of the studied cases, MIR SC generation based on ChG fibers always occurs with pump pulses in the anomalous dispersion regime of the fiber with a single ZDW. The SC broadening mechanisms are mainly soliton effects where higher order solitons break down into a series of fundamental solitons, accompanied by the emission of dispersive waves in the normal dispersion regime. This process produces a spectrum with a complex structure, which is sensitive to laser shot noise due to the increase in noise amplification through modulation instability gain, resulting in different spectral components $[106,159,162]$. There is low coherence across the bandwidth due to the fluctuations in the relative phase and intensity, limiting the resolution or precision for specific applications.

However, SCs generated from fibers pumped with periodic and ultrashort pulse trains can exhibit strong correlations between different pulses when the spectral broadening mechanism is highly reproducible, even though these pulses may still have complex spectral intensity and phase profiles [20]. A commonly used method for generating coherent SCs is to pump fibers with optimized all-normal dispersion (ANDi) profiles by using ultrashort lasers [164-166]. These fibers have low and flattened normal dispersion over the entire spectral region of interest. The SC spectral broadening in these cases is mainly caused by SPM and OWB, which can maintain a deterministic phase relationship between the newly generated wavelengths and the pump pulse, eliminating noise-sensitive soliton dynamics [165-167]. Consequently, highly coherent SCs can be obtained from such fibers. Coherent SCs based on ChG fibers with ANDi profiles have been reported in several experiments and simulations $[140,143,168,169]$. Liu et al. [168] used a ChG MOF with a core material of AsSe $\mathrm{A}_{2}$ and four air holes replaced by $\mathrm{As}_{2} \mathrm{~S}_{5}$ glass rods to engineer the dispersion to ANDi. A coherent SC extended to $3.3 \mu \mathrm{m}$ was generated in a 2-cm-long, all-solid MOF pumped by a $2.7 \mu \mathrm{m}$ laser with a pulse duration of $200 \mathrm{fs}$. The tapering of ChG fibers can be used as an alternative method to achieve ANDi profiles $[153,170]$. A 3-mm-long $\mathrm{As}_{2} \mathrm{~S}_{3}$ microwire, coated with PMMA, was tapered to a diameter of $0.58 \mu \mathrm{m}$, and exhibited normal dispersion at all wavelengths. When pumped with a $1550 \mathrm{~nm}$ laser with a pulse duration of $590 \mathrm{fs}$, the generated SC covered more than an octave of bandwidth, from $960 \mathrm{~nm}$ to $>2500 \mathrm{~nm}$, but the coherence property was not discussed in the literature [69]. Liu et al. [171] numerically investigated the coherence properties of MIR SC generation in tapered $\mathrm{AsSe}_{2}-\mathrm{As}_{2} \mathrm{~S}_{5}$ ChG fibers pumped at a wavelength of $4 \mu \mathrm{m}$ with a pulse duration of $500 \mathrm{fs}$. Figure 11 shows the spectrum evolutions and the corresponding degrees of coherence in two tapered fibers with different structures. It can be seen that the coherence of SC was decreased when the fiber ZDW hit the pump wavelength where solitons were generated, implying that soliton dynamics and noise amplification through modulation instability are the major reasons for SC decoherence.

Another approach for generating coherent and recompressible SCs is the suppression of soliton fission in fibers with two closely-spaced ZDWs centered near the pump [172]. Diouf et al. [173] designed a solid core MOF consisting of a three-ring, triangular lattice with some air holes in 
an $\mathrm{As}_{38.3} \mathrm{Se}_{61.2}$ glass host. The MOF with an air-hole diameter of $0.9 \mu \mathrm{m}$ had two ZDWs: $\sim 3.25 \mu \mathrm{m}$ and $\sim 4.25 \mu \mathrm{m}$. The study's numerical results show that a coherent SC with a spectral bandwidth of $>2 \mu \mathrm{m}$ was generated when $50 \mathrm{fs}$ pulses were pumped at $3.7 \mu \mathrm{m}$, but the coherence was not as high as that from the fibers with ANDi profiles. This result can be attributed to modulation instability which plays a role in the anomalous dispersion regime. Despite the lack of extremely high coherence, the SCs were successfully applied in coherent anti-Stokes Raman scattering microscopy [174]. Reducing the distance between two or more ZDWs can effectively eliminate modulation instability during nonlinear processes and subsequently generate highly coherent SC sources.
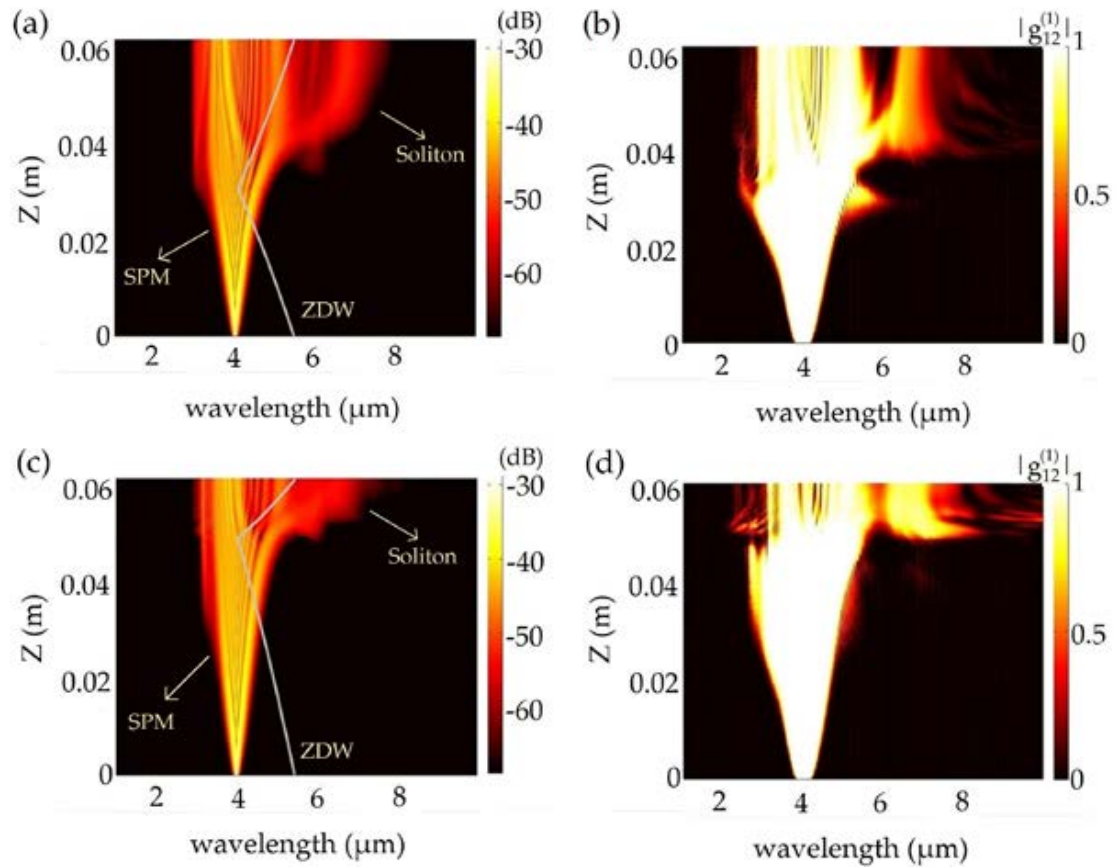

Figure 11. (a) and (c) are spectrum evolutions in two tapered fibers with different structures; (b) and (d) are the corresponding degrees of coherence (reproduced with permission from [170], copyright AIP Publishing, 2016).

\section{Toward All-Fiber SC Sources Based on ChG Fibers}

Many distinguished achievements have been made in MIR SC generation by using ChG fibers, and most of this work has employed free-space systems. However, these systems are generally unsuitable for practical applications, since OPA and OPO are typically complex and expensive [107,108]. Therefore, it is necessary to achieve all-fiber and alignment-free broadband SC sources with high-power spectral densities. To achieve this goal, much effort has been put into developing all-fiber systems.

Fiber-based SC generation based on amplifier pumping sources or fiber lasers has the advantages of having a much smaller size, lower weight, and power consumption, and much more rugged packaging. Thus, it has the potential to offer robust, compact, and low-cost solutions. MIR laser sources with good compactness and beam quality show great potential in all-fiber and broadband SC generation. On one hand, multistage master oscillator power amplifiers (MOPAs) have been successfully used as pump sources for all-fiber MIR SC generation in ChG fibers. A typical schematic of such a pumping system is shown in Figure 12, in which a $1.55 \mu \mathrm{m}$ seed laser is amplified in multiple stages and Raman-shifted in highly nonlinear fibers into the IR range to pump ChG fibers which are used in the last stage. By adopting this type of pumping scheme, Shaw and Gattass et al. $[98,99]$ achieved SCs with spectral coverages of 1.5-5 $\mu \mathrm{m}$ (140 mW output power) and 1.9-4.8 $\mu \mathrm{m}(565 \mathrm{~mW}$ output power), respectively, by using 2-m-long step-index $\mathrm{As}_{2} \mathrm{~S}_{3}$ fibers with a core/cladding diameter of $10 / 140 \mu \mathrm{m}$ and an NA of 0.3 . On the other hand, MIR lasers can usually be obtained from non-silica 
fibers doped with rare-earth ions. By doping $\mathrm{Er}^{3+}, \mathrm{Ho}^{3+}, \mathrm{Pr}^{3+}$, or $\mathrm{Dy}^{3+}$ ions into fluoride fibers, laser transitions of around 3.0 [175-178], 3.5 [179] and $3.9 \mu \mathrm{m}$ [180] have been realized. Hudson et al. [181] recently achieved an SC generation $(1.8-9.5 \mu \mathrm{m})$ with an average power of more than $30 \mathrm{~mW}$ by pumping an $\mathrm{As}_{2} \mathrm{Se}_{3}$ taper with a 4-m-long $\mathrm{Ho}^{3+} / \mathrm{Pr}^{3+}$ co-doped ZBLAN fiber laser which emitted a stable fs pulse train of $2874 \mathrm{~nm}$, with an average power of $140 \mathrm{~mW}$, at a repetition rate of $42 \mathrm{MHz}$. Moreover, MIR lasers can also be achieved using nonlinear gain through optical frequency conversions in passive non-silica fibers [182]. For example, by using a low-loss Fabry-Pérot cavity, formed by a pair of Bragg gratings written into a single-mode $\mathrm{As}_{2} \mathrm{~S}_{3}$ fiber, Raman fiber lasers at a wavelength of $3.34 \mu \mathrm{m}$ and a peak power of $0.6 \mathrm{~W}$, and a wavelength of $3.77 \mu \mathrm{m}$ and a peak power of $112 \mathrm{~mW}$ were reported by Martin Bernier et al. in refs. [183] and [184], respectively. These achievements represent an important step towards the development of compact laser sources operating in the MIR.

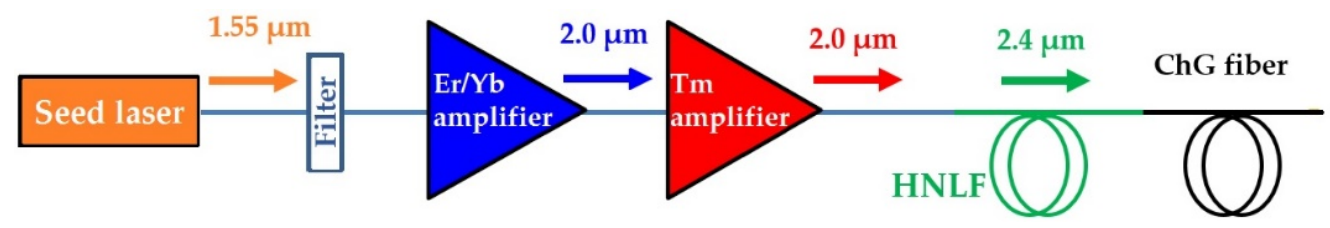

Figure 12. A typical schematic of fiber-based SC generation based on amplifier pumping sources. HNLF, highly nonlinear fiber.

However, for fiber lasers doped with rare-earth ions, many wavelengths cannot be accessed by using rare-earth gain alone [185]. For Raman fiber lasers, the Raman lasing process is highly restricted to the Raman gain of host glasses and reflected wavelengths of fiber Bragg gratings [186]. Once Raman fiber lasers are fabricated, the output wavelengths cannot be changed. Furthermore, the peak powers of Raman lasers are too low to reach the SC broadening thresholds. These disadvantages limit the practical flexibility and wavelength tunability of Raman fiber lasers as pump sources in the MIR region.

Alternatively, cascading approaches have been demonstrated, where a fiber-based SC is used to pump ChG fibers to further extend the spectral coverage [187-191]. This cascading approach is mainly based on the SC spectrum that contains many solitons with fs pulses and high peak powers in the long wavelength range from the first fiber with anomalous dispersion [2]. As long as the second fiber has a ZDW below the SC long wavelength edge, the solitons can continue to redshift in the second fiber when two fibers are cascading, which can then lead to wide SC generation. In 2014, Kubat et al. [187] numerically proposed a cascading scheme for SC generation in ChGs pumped with MIR SC sources (Figure 13), where the SC was extended to $9 \mu \mathrm{m}$ in a 10-cm-long $\mathrm{As}_{2} \mathrm{Se}_{3} \mathrm{MOF}$ with a core diameter of $5 \mu \mathrm{m}$ by pumping with a $0.9-4.1 \mu \mathrm{m}$ SC generated from a ZBLAN fiber. The ZBLAN fiber was chosen as the first fiber in the cascading scheme because of its following excellent properties: high damage threshold; ability to generate SC sources with $>3.5 \mu \mathrm{m}$ long wavelength edges extending above the ZDW of typical step-index ZBLAN fibers (around $1.6 \mu \mathrm{m}$ ); and high output powers of 13 [192], 15.2 [190], and even 21.8 W [193]. Petersen et al. [189] experimentally demonstrated an SC spectrum which was extended to $7 \mu \mathrm{m}$ with an output power of $6.5 \mathrm{~mW}$ in an $\mathrm{As}_{38} \mathrm{Se}_{62} \mathrm{SCF}$ with a 4 - $\mu \mathrm{m}$-core, pumped by an SC source with along wavelength edge of $4.4 \mu \mathrm{m}$ and power of $51.4 \mathrm{~mW}$, from a 5-m-long ZBLAN fiber with a carefully designed dispersion. Yin et al. [194] adopted a thulium-doped fiber amplifier (a 2-2.5 $\mu \mathrm{m}$ SC source with a maximum output power of $\sim 1 \mathrm{~W}$ ) to generate a 2-4.2 $\mu \mathrm{m}$ SC source in a 12-m-long ZBLAN fiber, which was then used as the pump light for an $\mathrm{As}_{2} \mathrm{~S}_{3}$ step-index fiber. Spectrally flat $2-5 \mu \mathrm{m}$ SC generation with a high power of $57.6 \mathrm{~mW}$ was eventually realized. Furthermore, Robichaud et al. [188] adopted a 3-4.2 $\mu \mathrm{m}$ SC source from a 1-m-long $\mathrm{ZrF}_{4}$ fiber pumped with an Er-doped $\mathrm{ZrF}_{4}$ fiber amplifier to excite a low-loss $\mathrm{As}_{2} \mathrm{Se}_{3}$ fiber. As a result, a MIR SC source spanning from 3 to $8 \mu \mathrm{m}$ with an output power of $1.5 \mathrm{~mW}$ was demonstrated. 

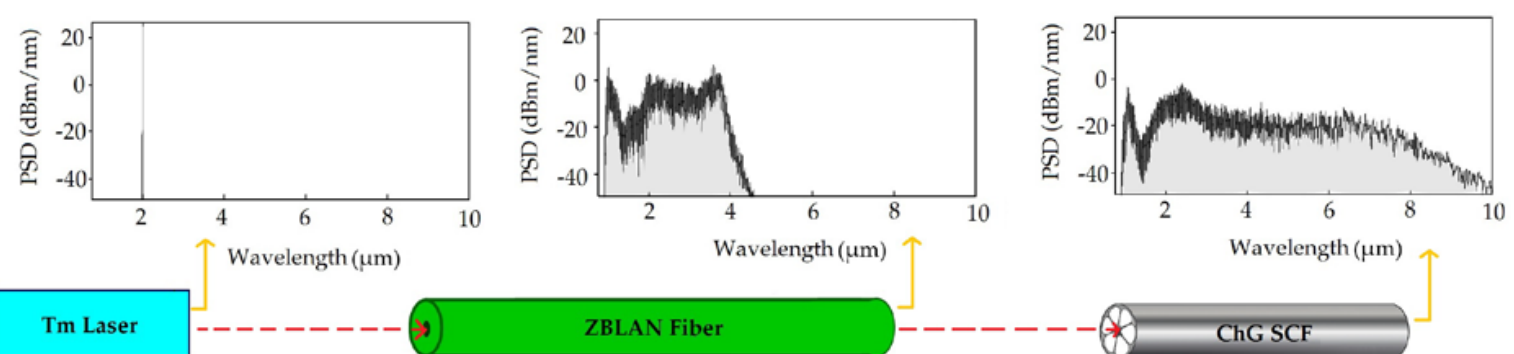

Figure 13. Numerically setup of cascading MIR SC source (reproduced with permission from [187], copyright Optical Society of America, 2014).

Recently, Martinez et al. [195] utilized a MOPA to pump cascading ZBLAN, $\mathrm{As}_{2} \mathrm{~S}_{3}$, and $\mathrm{As}_{2} \mathrm{Se}_{3}$ fibers. Figure 14a shows the corresponding setup for $\mathrm{SC}$ generation. The $\mathrm{As}_{2} \mathrm{~S}_{3}$ fiber was excited by the SC sources that were extended to $4.5 \mu \mathrm{m}$ from the ZBLAN fiber. Actually, the $\mathrm{As}_{2} \mathrm{~S}_{3}$ fiber played an exceptional role as an intermediary between the ZBLAN and $\mathrm{As}_{2} \mathrm{Se}_{3}$ fibers because of its high power handling capability. When the pulse's repetition rate was scaled up to $800 \mathrm{kHz}$, the cascading SC generation shown in Figure 14b spanned a broadband spectrum, from 1.6 to $>11 \mu \mathrm{m}$, from the $\mathrm{As}_{2} \mathrm{Se}_{3}$ step-index fibers, and produced a high output power of $417 \mathrm{~mW}$. Such an SC generation exhibited the wide spectral coverage and high average power required for practical applications.

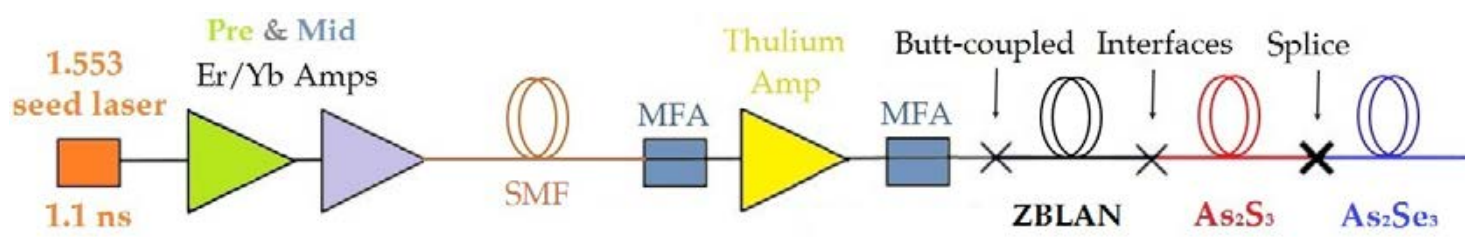

(a)

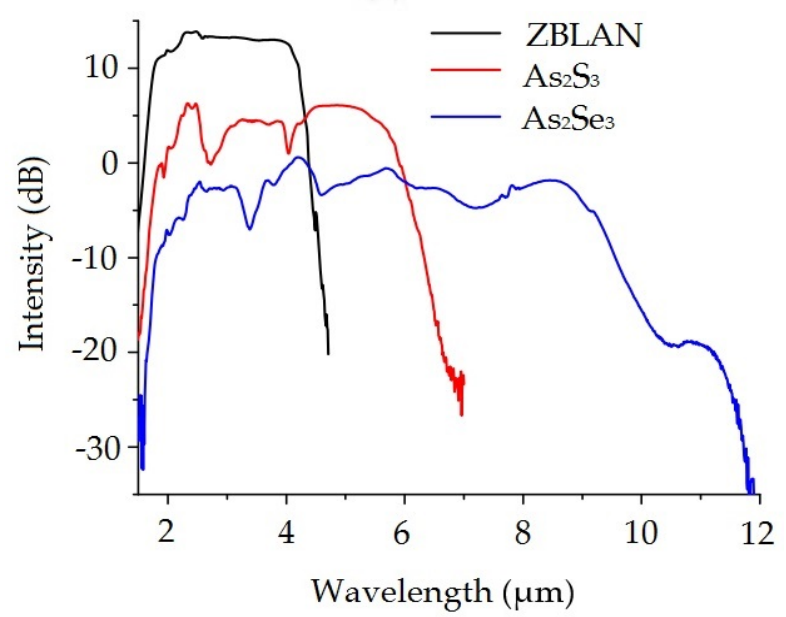

(b)

Figure 14. (a) Setup of MOPA and cascading scheme for all-fiber SC generation. (b) Measured SC spectra from ZBLAN (black), $\mathrm{AS}_{2} \mathrm{~S}_{3}$ (red), and $\mathrm{As}_{2} \mathrm{Se}_{3}$ (blue) fibers (reproduced with permission from [195], copyright Optical Society of America, 2018).

All-fiber MIR SC generation based on ChG fibers is the development trend for the future. However, although levels of hundreds of $\mathrm{mW}$ have been reached, the output powers of SC sources generated from ChG fibers still need to be improved. On one hand, the pump power injected into ChG fibers needs to be increased by adjusting the repetition rate and pulse width of the seed sources to reach a W level average power range. On the other hand, the propagation losses of the all-fiber system 
need to be reduced significantly. Actually, a large portion of the system loss results from the high Fresnel reflection of ChG fibers due to the coupling methods used between them and other fibers, such as lens focusing, butt-coupling, and mechanical splicing, which may also affect the fiber end facet-specifically its environmental stability and power tolerance capability. The fusion splicing between ChG with other fibers, especially ZBLAN fibers, needs be applied to reduce the high Fresnel reflection. Silica with ZBLAN fibers or ChG fibers, spliced by fusion, have been successfully developed and used for SC generation [190,196-198]. If these two technologies can be improved and applied for the splicing of ChG and ZBLAN fibers, they will have great potential to produce all-fiber-scheme SC sources with high average output powers. This would allow, the robustness, reliability, and practicality of MIR SC sources to be ensured for long-term applications.

\section{Conclusions}

Considerable progress has been made in MIR SC generation from ChG fibers over the past decade due to the advantages of a wide transparency window and high optical nonlinearity. Wide MIR SC spectra $(>7 \mu \mathrm{m})$ have been obtained in ChG step-index fibers, MOFs, and tapered fibers, while ultrabroad SC spectra $(>13 \mu \mathrm{m})$ have been realized in ChG fibers of $\mathrm{cm}$-level fiber length when pumped with an MIR OPA. In particular, the broadest SC spectrum (from 2 to $16 \mu \mathrm{m}$ ) covering the entire MIR molecular fingerprint region was achieved with a novel Ge-Te-AgI ChG fiber [126]. In addition, the use of MIR SC sources spanning 2-7.5 $\mu \mathrm{m}$ from a ChG fiber in multispectral tissue imaging at wavelengths beyond $5 \mu \mathrm{m}$ has been reported very recently [5].

MOFs and tapered fibers have great flexibility in dispersion engineering, resulting in multiple options on pump sources. A small $A_{\text {eff }}$ and a large $\gamma$ make the nonlinear power intensity dependent effects significant, which can efficiently broaden the SC spectrum. However, extra losses induced by exposure to the external environment in MOFs and the use of tapered fibers with insufficient taper waist diameters can reduce transmission efficiency. Step-index fibers have high power handling capacity and mechanical strength, which is conducive to practical applications and equipment stability. Nevertheless, the output power of the SC generation from ChG fibers is generally low, and the maximum output power has been reported to be $565 \mathrm{~mW}$ [99]. This will impose barriers to practical applications. Therefore, it is necessary to improve the output power by optimizing the pump scheme or using novel ChG fibers with a high threshold against laser damage. As a unique spectral characteristic, the coherence of MIR SC sources is also a significant consideration for practical applications.

Although broadband MIR SCs can be generated from ChG fibers when pumped by OPA or OPO, these systems are generally unsuitable for practical applications, since the complexity and costliness of OPA and OPO sacrifice system robustness and compactness. Currently, MIR SC sources from ChG fibers are being developed as all-fiber optics. The most effective pump scheme to achieve all-fiber $\mathrm{SC}$ sources is to cascade ChG fibers to ZBLAN fibers which are pumped with MOPAs. However, it is imperative to improve the key technology of reliable, low-loss fusion splicing between silica and ZBLAN fibers, and between ZBLAN and ChG fibers. MIR SC sources with good performance from ChG fibers are likely to become commercially available in the near future.

Author Contributions: S.D. conceived and designed the structure of this review; S.D. and Y.W. wrote the paper; all authors contributed to the discussion and revision of the paper.

Acknowledgments: The authors acknowledge the National Natural Science Foundation of China (NSFC) (Grants No. 61435009, 61627815) and the K. C. Wong Magna Fund in Ningbo University.

Conflicts of Interest: The authors declare no conflict of interest. 


\section{Abbreviations}

The following abbreviations are used in this manuscript:

$\begin{array}{ll}\text { ANDi } & \text { All-normal dispersion } \\ \text { ChG } & \text { Chalcogenide } \\ \text { FIR } & \text { Far-infrared } \\ \text { IR } & \text { Infrared } \\ \text { MIR } & \text { Mid-infrared } \\ \text { MOF } & \text { Microstructured optical fiber } \\ \text { MOPA } & \text { Master oscillator power amplifier } \\ \text { NA } & \text { Numerical aperture } \\ \text { OPA } & \text { Optical parametric amplifier } \\ \text { OPO } & \text { Optical parametric oscillator } \\ \text { OWB } & \text { Optical wave break } \\ \text { PCF } & \text { Photonic crystal fiber } \\ \text { SC } & \text { Supercontinuum } \\ \text { SCF } & \text { Suspended-core fiber } \\ \text { SPM } & \text { Self phase modulation } \\ \text { SRS } & \text { Stimulated Raman scattering } \\ \text { ZBLAN } & \text { ZrF }_{4}-\text { BaF }_{2}-\text { LaF }_{3}-\mathrm{AlF}_{3}-\mathrm{NaF} \\ \text { ZDW } & \text { Zero dispersion wavelength } \\ \text { ZMDW } & \text { Zero material dispersion wavelength }\end{array}$

\section{References}

1. Alfano, R.R.; Shapiro, S.L. Observation of self-phase modulation and small-scale filaments in crystals and glasses. Phys. Rev. Lett. 1970, 24, 592-594. [CrossRef]

2. Dudley, J.M.; Genty, G.; Coen, S. Supercontinuum generation in photonic crystal fiber. Rev. Mod. Phys. 2006, 78, 1135-1184. [CrossRef]

3. Ke, K.; Xia, C.; Islam, M.N.; Welsh, M.J.; Freeman, M.J. Mid-infrared absorption spectroscopy and differential damage in vitro between lipids and proteins by an all-fiber-integrated supercontinuum laser. Opt. Express 2009, 17, 12627-12640. [CrossRef] [PubMed]

4. Dupont, S.; Petersen, C.; Thøgersen, J.; Agger, C.; Bang, O.; Keiding, S.R. IR microscopy utilizing intense supercontinuum light source. Opt. Express 2012, 20, 4887-4892. [CrossRef] [PubMed]

5. Petersen, C.R.; Prtljaga, N.; Farries, M.; Ward, J.; Napier, B.; Lloyd, G.R.; Nallala, J.; Stone, N.; Bang, O. Mid-infrared multispectral tissue imaging using a chalcogenide fiber supercontinuum source. Opt. Lett. 2018, 43, 999-1002. [CrossRef] [PubMed]

6. Seddon, A.B. A prospective for new mid-infrared medical endoscopy using chalcogenide glasses. Int. J. Appl. Glass Sci. 2011, 2, 177-191. [CrossRef]

7. Eggleton, B.J.; Luther-Davies, B.; Richardson, K. Chalcogenide photonics. Nat. Photonics 2011, 5, 141-148. [CrossRef]

8. Kumar, M.; Islam, M.N.; Terry, F.L.; Freeman, M.J.; Chan, A.; Neelakandan, M.; Manzur, T. Stand-off detection of solid targets with diffuse reflection spectroscopy using a high-power mid-infrared supercontinuum source. Appl. Opt. 2012, 51, 2794-2807. [CrossRef] [PubMed]

9. Qin, G.; Yan, X.; Kito, C.; Liao, M.; Chaudhari, C.; Suzuki, T.; Ohishi, Y. Ultrabroadband supercontinuum generation from ultraviolet to $6.28 \mu \mathrm{m}$ in a fluoride fiber. Appl. Phys. Lett. 2009, 95, 161103. [CrossRef]

10. Swiderski, J.; Michalska, M.; Maze, G. Mid-IR supercontinuum generation in a ZBLAN fiber pumped by a gain-switched mode-locked Tm-doped fiber laser and amplifier system. Opt. Express 2013, 21, 7851-7857. [CrossRef] [PubMed]

11. Xia, C.; Kumar, M.; Kulkarni, O.P.; Islam, M.N.; Terry, J.F.L.; Freeman, M.J.; Poulain, M.; Mazé, G. Mid-infrared supercontinuum generation to $4.5 \mu \mathrm{m}$ in ZBLAN fluoride fibers by nanosecond diode pumping. Opt. Lett. 2006, 31, 2553-2555. [CrossRef] [PubMed] 
12. Picot-Clemente, J.; Strutynski, C.; Amrani, F.; Désévédavy, F.; Jules, J.C.; Gadret, G.; Deng, D.; Cheng, T.; Nagasaka, K.; Ohishi, Y.; et al. Enhanced supercontinuum generation in tapered tellurite suspended core fiber. Opt. Commun. 2015, 354, 374-379. [CrossRef]

13. Liao, M.; Gao, W.; Duan, Z.; Yan, X.; Suzuki, T.; Ohishi, Y. Supercontinuum generation in short tellurite microstructured fibers pumped by a quasi-cw laser. Opt. Lett. 2012, 37, 2127-2129. [CrossRef] [PubMed]

14. Domachuk, P.; Wolchover, N.A.; Cronin-Golomb, M.; Wang, A.; George, A.K.; Cordeiro, C.M.B.; Knight, J.C.; Omenetto, F.G. Over $4000 \mathrm{~nm}$ bandwidth of mid-IR supercontinuum generation in sub-centimeter segments of highly nonlinear tellurite PCFs. Opt. Express 2008, 16, 7161-7168. [CrossRef] [PubMed]

15. Hamed, S.; Mohammad, K.M.; Majid, E.; Moghadasi, M.N. Ultra-wide mid-infrared supercontinuum generation in $\mathrm{As}_{40} \mathrm{Se}_{60}$ chalcogenide fibers solid core PCF versus SIF. IEEE J. Sel. Top. Quantum Electron. 2016, 22. [CrossRef]

16. Wei, D.P.; Galstian, T.V.; Smolnikov, I.V.; Plotnichenko, V.G.; Zohrabyan, A. Spectral broadening of femtosecond pulses in a single-mode As-S glass fiber. Opt. Express 2005, 13, 2439-2443. [CrossRef] [PubMed]

17. Kubat, I.; Agger, C.S.; Møller, U.; Seddon, A.B.; Tang, Z.; Sujecki, S.; Benson, T.M.; Furniss, D.; Lamrini, S.; Scholle, K.; et al. Mid-infrared supercontinuum generation to $12.5 \mu \mathrm{m}$ in large NA chalcogenide step-index fibres pumped at $4.5 \mu \mathrm{m}$. Opt. Express 2014, 22, 19169-19182. [CrossRef] [PubMed]

18. Shiryaev, V.S.; Churbanov, M.F. Trends and prospects for development of chalcogenide fibers for mid-infrared transmission. J. Non-Cryst. Solids 2013, 377, 225-230. [CrossRef]

19. Slusher, R.E.; Lenz, G.; Hodelin, J.; Sanghera, J.; Shaw, L.B.; Aggarwal, I.D. Large raman gain and nonlinear phase shifts in high-purity $\mathrm{As}_{2} \mathrm{Se}_{3}$ chalcogenide fibers. J. Opt. Soc. Am. B 2004, 21, 1146-1155. [CrossRef]

20. Price, J.H.V.; Feng, X.; Heidt, A.M.; Brambilla, G.; Horak, P.; Poletti, F.; Ponzo, G.; Petropoulos, P.; Petrovich, M.; Shi, J.; et al. Supercontinuum generation in non-silica fibers. Opt. Fiber Technol. 2012, 18, 327-344. [CrossRef]

21. Borisova, Z.U. Glassy Semiconductors; Springer: New York, NY, USA, 1981.

22. Tao, G.; Ebendorff-Heidepriem, H.; Stolyarov, A.M.; Danto, S.; Badding, J.V.; Fink, Y.; Ballato, J.; Abouraddy, A.F. Infrared fibers. Adv. Opt. Photonics 2015, 7, 379. [CrossRef]

23. Han, Z.; Singh, V.; Kita, D.; Monmeyran, C.; Becla, P.; Su, P.; Li, J.; Huang, X.; Kimerling, L.C.; Hu, J.; et al. On-chip chalcogenide glass waveguide-integrated mid-infrared PbTe detectors. Appl. Phys. Lett. 2016, 109, 071111. [CrossRef]

24. Smektala, F.; Quemard, C.; Couderc, V.; Barthélémy, A. Non-linear optical properties of chalcogenide glasses measured by Z-scan. J. Non-Cryst. Solids 2000, 274, 232-237. [CrossRef]

25. Smektala, F.; Quemard, C.; Leneindre, L.; Lucas, J.; Barthélémy, A.; De Angelis, C. Chalcogenide glasses with large non-linear refractive indices. J. Non-Cryst. Solids 1998, 239, 139-142. [CrossRef]

26. Monro, T.M.; Ebendorff-Heidepriem, H. Progress in microstructured optical fibers. Annu. Rev. Mater. Res. 2006, 36, 467-495. [CrossRef]

27. Kapany, N.S.; Simms, R.J. Recent developments in infrared fiber optics. Infrared Phys. 1965, 5, 69-80. [CrossRef]

28. Churbanov, M.F. High-purity chalcogenide glasses as materials for fiber optics. J. Non-Cryst. Solids 1995, 184, 25-29. [CrossRef]

29. Shiryaev, V.S.; Adam, J.L.; Zhang, X.H.; Boussard-Plédel, C.; Lucas, J.; Churbanov, M.F. Infrared fibers based on Te-As-Se glass system with low optical losses. J. Non-Cryst. Solids 2004, 336, 113-119. [CrossRef]

30. Shiryaev, V.S.; Troles, J.; Houizot, P.; Ketkova, L.A.; Churbanov, M.F.; Adam, J.L.; Sibirkin, A.A. Preparation of optical fibers based on Ge-Sb-S glass system. Opt. Mater. 2009, 32, 362-367. [CrossRef]

31. Nguyen, V.Q.; Sanghera, J.S.; Cole, B.; Pureza, P.; Kung, F.H.; Aggarwal, I.D. Fabrication of arsenic sulfide optical fiber with low hydrogen impurities. J. Am. Ceram. Soc. 2002, 85, 2056-2058. [CrossRef]

32. Xu, D.; Dai, S.; You, C.; Wang, Y.; Han, X.; Lin, C.; Liu, Y.; Liu, Z.; Wang, X.; Xu, Y.; et al. Optimization of draw processing parameters for $\mathrm{As}_{2} \mathrm{Se}_{3}$ glass fiber. Opt. Fiber Technol. 2017, 38, 46-50. [CrossRef]

33. El-Amraoui, M.; Gadret, G.; Jules, J.C.; Fatome, J.; Fortier, C.; Désévédavy, F.; Skripatchev, I.; Messaddeq, Y.; Troles, J.; Brilland, L.; et al. Microstructured chalcogenide optical fibers from $\mathrm{As}_{2} \mathrm{~S}_{3}$ glass: Towards new IR broadband sources. Opt. Express 2010, 18, 26655-26665. [CrossRef] [PubMed]

34. Sun, Y.N.; Dai, S.; Zhang, P.; Wang, X.; Xu, Y.; Liu, Z.; Chen, F.; Wu, Y.; Zhang, Y.; Wang, R.; et al. Fabrication and characterization of multimaterial chalcogenide glass fiber tapers with high numerical apertures. Opt. Express 2015, 23, 23472-23483. [CrossRef] [PubMed] 
35. IR Fibers. Available online: http://coractive.com/products/mid-ir-fibers-lasers/ir-fibers/index.html (accessed on 20 March 2018).

36. IRflex. Available online: https://www.irflex.com/products/ (accessed on 20 March 2018).

37. Wang, Y.; Boolchand, P.; Micoulaut, M. Glass structure, rigidity transitions and the intermediate phase in the Ge-As-Se ternary. Europhys. Lett. 2000, 52, 633-639. [CrossRef]

38. Gopinath, J.T.; Soljačić, M.; Ippen, E.P.; Fuflyigin, V.N.; King, W.A.; Shurgalin, M. Third order nonlinearities in Ge-As-Se-based glasses for telecommunications applications. J. Appl. Phys. 2004, 96, 6931-6933. [CrossRef]

39. Toupin, P.; Brilland, L.; Trolès, J.; Adam, J.-L. Small core Ge-As-Se microstructured optical fiber with single-mode propagation and low optical losses. Opt. Mater. Express 2012, 2, 1359-1366. [CrossRef]

40. Shiryaev, V.S.; Churbanov, M.F.; Dianov, E.M.; Plotnichenko, V.G.; Adam, J.L.; Lucas, J. Recent progress in preparation of chalcogenide As-Se-Te glasses with low impurity content. Optoelectron. Adv. Mater. 2005, 7, 1773-1779.

41. Churbanov, M.F.; Shiryaev, V.S.; Suchkov, A.I.; Pushkin, A.A.; Gerasimenko, V.V.; Shaposhnikov, R.M.; Dianov, E.M.; Plotnichenko, V.G.; Koltashev, V.V.; Pyrkov, Y.N.; et al. High-purity As-S-Se and As-Se-Te glasses and optical fibers. Inorg. Mater. 2007, 43, 441-447. [CrossRef]

42. Delaizir, G.; Dussauze, M.; Nazabal, V.; Lecante, P.; Dollé, M.; Rozier, P.; Kamitsos, E.I.; Jovari, P.; Bureau, B. Structural characterizations of As-Se-Te glasses. J. Alloys Compd. 2011, 509, 831-836. [CrossRef]

43. Mairaj, A.K.; Hua, P.; Rutt, H.N.; Hewak, D.W. Fabrication and characterization of continuous wave direct uv $(\lambda=244 \mathrm{~nm})$ written channel waveguides in chalcogenide (Ga:La:S) glass. J. Lightwave Technol. 2002, 20, 1578-1584. [CrossRef]

44. Petrovich, M.N.; Favre, A.; Hewak, D.W.; Rutt, H.N.; Grippo, A.C.; Gubeli, J.F.; Jordan, K.C.; Neil, G.R.; Shinn, M.D. Near-IR absorption of Ga:La:S and Ga:La:S:O glasses by free-electron laser-based laser calorimetry. J. Non-Cryst. Solids 2003, 326-327, 93-97. [CrossRef]

45. Nistreanu, A.; Enachi, N.; Iovu, M.; Koroli, V.; Furniss, D.; Seddon, A. The spontaneous emission probabilities for Ga-La-S:Pr ${ }^{3+}$ glass. J. Optoelectron. Adv. Mater. 2010, 12, 800-805.

46. Wang, R.P.; Zha, C.J.; Rode, A.V.; Madden, S.J.; Luther-Davies, B. Thermal characterization of Ge-As-Se glasses by differential scanning calorimetry. J. Mater. Sci. Mater. Electron. 2007, 18, 419-422. [CrossRef]

47. Yang, Z.; Gulbiten, O.; Lucas, P.; Luo, T.; Jiang, S. Long-wave infrared-transmitting optical fibers. J. Am. Ceram. Soc. 2011, 94, 1761-1765. [CrossRef]

48. Sivakumaran, K.; Nair, C.K.S. Rapid synthesis of chalcogenide glasses of Se-Te-Sb system by microwave irradiation. J. Phys. D Appl. Phys. 2005, 38, 2476. [CrossRef]

49. Thompson, D.; Danto, S.; Musgraves, J.D.; Wachtel, P.; Giroire, B.; Richardson, K. Microwave assisted synthesis of high purity $\mathrm{As}_{2} \mathrm{Se}_{3}$ chalcogenide glasses. Phys. Chem. Glasses B 2013, 54, 27-34.

50. Katsuyama, T.; Satoh, S.; Matsumura, H. Fabrication of high-purity chalcogenide glasses by chemical vapor deposition. J. Appl. Phys. 1986, 59, 1446-1449. [CrossRef]

51. Sanghera, J.S.; Aggarwal, I.D. Active and passive chalcogenide glass optical fibers for IR applications: A review. J. Non-Cryst. Solids 1999, 256-257, 6-16. [CrossRef]

52. Sanghera, J.S.; Florea, C.M.; Shaw, L.B.; Pureza, P.; Nguyen, V.Q.; Bashkansky, M.; Dutton, Z.; Aggarwal, I.D. Non-linear properties of chalcogenide glasses and fibers. J. Non-Cryst. Solids 2008, 354, 462-467. [CrossRef]

53. Zhang, X.; Ma, H.; Lucas, J. Applications of chalcogenide glass bulks and fibres. J. Optoelectron. Adv. Mater. 2003, 5, 1327-1333.

54. Sanghera, J.S.; Aggarwal, I.D. Development of chalcogenide glass fiber optics at NRL. J. Non-Cryst. Solids 1997, 213-214, 63-67. [CrossRef]

55. Zhang, B.; Guo, W.; Yu, Y.; Zhai, C.; Qi, S.; Yang, A.; Li, L.; Yang, Z.; Wang, R.; Tang, D. Low loss, high NA chalcogenide glass fibers for broadband mid-infrared supercontinuum generation. J. Am. Ceram. Soc. 2015, 98, 1389-1392. [CrossRef]

56. Nishii, J.; Yamashita, T.; Yamagishi, T. Low-loss chalcogenide glass fiber with core-cladding structure. Appl. Phys. Lett. 1988, 53, 553-554. [CrossRef]

57. Furniss, D.; Seddon, A.B. Towards monomode proportioned fibreoptic preforms by extrusion. J. Non-Cryst. Solids 1999, 256, 232-236. [CrossRef]

58. Jiang, C.; Wang, X.; Zhu, M.; Xu, H.; Nie, Q.; Dai, S.; Tao, G.; Shen, X.; Cheng, C.; Zhu, Q. Preparation of chalcogenide glass fiber using an improved extrusion method. Opt. Eng. 2016, 55, 056114. [CrossRef] 
59. Seddon, A.B.; Furniss, D.; Sojka, L.; Churbanov, M.F.; Sujecki, S.; Benson, T.M.; Shiryaev, V.S.; Tang, Z. Low loss Ge-As-Se chalcogenide glass fiber, fabricated using extruded preform, for mid-infrared photonics. Opt. Mater. Express 2015, 5, 1722-1737.

60. Churbanov, M.F.; Snopatin, G.E.; Shiryaev, V.S.; Plotnichenko, V.G.; Dianov, E.M. Recent advances in preparation of high-purity glasses based on arsenic chalcogenides for fiber optics. J. Non-Cryst. Solids 2011, 357, 2352-2357. [CrossRef]

61. Tao, G.; Shabahang, S.; Banaei, E.-H.; Kaufman, J.J.; Abouraddy, A.F. Multimaterial preform coextrusion for robust chalcogenide optical fibers and tapers. Opt. Lett. 2012, 37, 2751-2753. [CrossRef] [PubMed]

62. Ebendorff-Heidepriem, H. Non-silica microstructured optical fibers for infrared applications. In Proceedings of the 2014 OptoElectronics and Communication Conference and Australian Conference on Optical Fibre Technology, Melbourne, Australia, 6-10 July 2014.

63. Agrawal, G.P. Nonlinear Fiber Optics, 5th ed.; Springer: Berlin/Heidelberg, Germany, 2015; pp. $195-211$.

64. Walmsley, I.; Waxer, L.; Dorrer, C. The role of dispersion in ultrafast optics. Rev. Sci. Instrum. 2001, 72, 1-29. [CrossRef]

65. Li, L.; Abdukerim, N.; Rochette, M. Mid-infrared wavelength conversion from $\mathrm{As}_{2} \mathrm{Se}_{3}$ microwires. Opt. Lett. 2017, 42, 639-642. [CrossRef] [PubMed]

66. Asobe, M. Nonlinear optical properties of chalcogenide glass fibers and their application to all-optical switching. Opt. Fiber Technol. 1997, 3, 142-148. [CrossRef]

67. Finazzi, V.; Monro, T.M.; Richardson, D.J. Small-core silica holey fibers: Nonlinearity and confinement loss trade-offs. J. Opt. Soc. Am. B 2003, 20, 1427-1436. [CrossRef]

68. Hudson, D.D.; Dekker, S.A.; Mägi, E.C.; Judge, A.C.; Jackson, S.D.; Li, E.; Sanghera, J.S.; Shaw, L.B.; Aggarwal, I.D.; Eggleton, B.J. Octave spanning supercontinuum in an $\mathrm{As}_{2} \mathrm{~S}_{3}$ taper using ultralow pump pulse energy. Opt. Lett. 2011, 36, 1122-1124. [CrossRef] [PubMed]

69. Al-Kadry, A.; Li, L.; Amraoui, M.E.; North, T.; Messaddeq, Y.; Rochette, M. Broadband supercontinuum generation in all-normal dispersion chalcogenide microwires. Opt. Lett. 2015, 40, 4687-4690. [CrossRef] [PubMed]

70. Mägi, E.C.; Fu, L.B.; Nguyen, H.C.; Lamont, M.R.E.; Yeom, D.I.; Eggleton, B.J. Enhanced kerr nonlinearity in sub-wavelength diameter $\mathrm{As}_{2} \mathrm{Se}_{3}$ chalcogenide fiber tapers. Opt. Express 2007, 15, 10324-10329. [CrossRef] [PubMed]

71. Knight, J.C.; Birks, T.A.; Russell, P.S.J.; Atkin, D.M. All-silica single-mode optical fiber with photonic crystal cladding. Opt. Lett. 1996, 21, 1547-1549. [CrossRef] [PubMed]

72. Troles, J.; Coulombier, Q.; Canat, G.; Duhant, M.; Renard, W.; Toupin, P.; Calvez, L.; Renversez, G.; Smektala, F.; El Amraoui, M.; et al. Low loss microstructured chalcogenide fibers for large non linear effects at $1995 \mathrm{~nm}$. Opt. Express 2010, 18, 26647-26654. [CrossRef] [PubMed]

73. Russell, P. Photonic crystal fibers. Science 2003, 299, 358-362. [CrossRef] [PubMed]

74. Saghaei, H.; Ebnali-Heidari, M.; Moravvej-Farshi, M.K. Midinfrared supercontinuum generation via $\mathrm{As}_{2} \mathrm{Se}_{3}$ chalcogenide photonic crystal fibers. Appl. Opt. 2015, 54, 2072-2079. [CrossRef] [PubMed]

75. Renversez, G.; Kuhlmey, B.; McPhedran, R. Dispersion management with microstructured optical fibers: Ultraflattened chromatic dispersion with low losses. Opt. Lett. 2003, 28, 989-991. [CrossRef] [PubMed]

76. El-Amraoui, M.; Fatome, J.; Jules, J.C.; Kibler, B.; Gadret, G.; Fortier, C.; Smektala, F.; Skripatchev, I.; Polacchini, C.F.; Messaddeq, Y.; et al. Strong infrared spectral broadening in low-loss As-S chalcogenide suspended core microstructured optical fibers. Opt. Express 2010, 18, 4547-4556. [CrossRef] [PubMed]

77. Schuster, K.; Kobelke, J.; Grimm, S.; Schwuchow, A.; Kirchhof, J.; Bartelt, H.; Gebhardt, A.; Leproux, P.; Couderc, V.; Urbanczyk, W. Microstructured fibers with highly nonlinear materials. Opt. Quantum Electron. 2007, 39, 1057-1069. [CrossRef]

78. Monro, T.M.; Richardson, D.J. Holey optical fibres: Fundamental properties and device applications. C. R. Phys. 2003, 4, 175-186. [CrossRef]

79. SelenOptics. Available online: http:/ / www.selenoptics.com/ (accessed on 20 March 2018).

80. Cheng, T.; Kanou, Y.; Xue, X.; Deng, D.; Matsumoto, M.; Misumi, T.; Suzuki, T.; Ohishi, Y. Mid-infrared supercontinuum generation in a novel $\mathrm{AsSe}_{2}-\mathrm{As}_{2} \mathrm{~S}_{5}$ hybrid microstructured optical fiber. Opt. Express 2014, 22, 23019-23025. [CrossRef] [PubMed] 
81. Désévédavy, F.; Renversez, G.; Brilland, L.; Houizot, P.; Troles, J.; Coulombier, Q.; Smektala, F.; Traynor, N.; Adam, J.-L. Small-core chalcogenide microstructured fibers for the infrared. Appl. Opt. 2008, 47, 6014-6021. [CrossRef] [PubMed]

82. Brilland, L.; Smektala, F.; Renversez, G.; Chartier, T.; Troles, J.; Nguyen, T.N.; Traynor, N.; Monteville, A. Fabrication of complex structures of holey fibers in chalcogenide glass. Opt. Express 2006, 14, 1280-1285. [CrossRef] [PubMed]

83. Coulombier, Q.; Brilland, L.; Houizot, P.; Chartier, T.; N'Guyen, T.N.; Smektala, F.; Renversez, G.; Monteville, A.; Méchin, D.; Pain, T.; et al. Casting method for producing low-loss chalcogenide microstructured optical fibers. Opt. Express 2010, 18, 9107-9112. [CrossRef] [PubMed]

84. Toupin, P.; Brilland, L.; Méchin, D.; Adam, J.-L.; Troles, J. Optical aging of chalcogenide microstructured optical fibers. J. Lightwave Technol. 2014, 32, 2428-2432. [CrossRef]

85. Mouawad, O.; Kedenburg, S.; Steinle, T.; Steinmann, A.; Kibler, B.; Désévédavy, F.; Gadret, G.; Jules, J.C.; Giessen, H.; Smektala, F. Experimental long-term survey of mid-infrared supercontinuum source based on $\mathrm{As}_{2} \mathrm{~S}_{3}$ suspended-core fibers. Appl. Phys. B 2016, 122, 177. [CrossRef]

86. Mouawad, O.; Picot-Clémente, J.; Amrani, F.; Strutynski, C.; Fatome, J.; Kibler, B.; Désévédavy, F.; Gadret, G.; Jules, J.C.; Deng, D.; et al. Multioctave midinfrared supercontinuum generation in suspended-core chalcogenide fibers. Opt. Lett. 2014, 39, 2684-2687. [CrossRef] [PubMed]

87. Nielsen, M.D.; Vienne, G.; Folkenberg, J.R.; Bjarklev, A. Investigation of microdeformation-induced attenuation spectra in a photonic crystal fiber. Opt. Lett. 2003, 28, 236-238. [CrossRef] [PubMed]

88. Mortensen, N.A.; Folkenberg, J.R. Low-loss criterion and effective area considerations for photonic crystal fibres. J. Opt. A Pure Appl. Opt. 2003, 5, 163-167. [CrossRef]

89. Roberts, P.J.; Couny, F.; Sabert, H.; Mangan, B.J.; Birks, T.A.; Knight, J.C.; Russell, P.S.J. Loss in solid-core photonic crystal fibers due to interface roughness scattering. Opt. Express 2005, 13, 7779-7793. [CrossRef] [PubMed]

90. Coscelli, E.; Poli, F.; Li, J.; Cucinotta, A.; Selleri, S. Chalcogenide suspended-core fibers for supercontinuum generation in the mid-infrared. Proc. SPIE 2015, 9347. [CrossRef]

91. Mi, N.; Wu, B.; Jiang, L.; Sun, L.; Zhao, Z.; Wang, X.; Zhang, P.; Pan, Z.; Liu, Z.; Dai, S. Structure design and numerical evaluation of highly nonlinear suspended-core chalcogenide fibers. J. Non-Cryst. Solids 2017, 464, 44-50. [CrossRef]

92. Birks, T.A.; Li, Y.W. The shape of fiber tapers. J. Lightwave Technol. 1992, 10, 432-438. [CrossRef]

93. Kaufman, J.J.; Tao, G.; Shabahang, S.; Deng, D.S.; Fink, Y.; Abouraddy, A.F. Thermal drawing of high-density macroscopic arrays of well-ordered sub-5-nm-diameter nanowires. Nano Lett. 2011, 11, 4768-4773. [CrossRef] [PubMed]

94. Al-kadry, A.; Amraoui, M.E.; Messaddeq, Y.; Rochette, M. Two octaves mid-infrared supercontinuum generation in $\mathrm{As}_{2} \mathrm{Se}_{3}$ microwires. Opt. Express 2014, 22, 31131-31137. [CrossRef] [PubMed]

95. Baker, C.; Rochette, M. Highly nonlinear hybrid asse-pmma microtapers. Opt. Express 2010, 18, 12391-12398. [CrossRef] [PubMed]

96. Yeom, D.-I.; Mägi, E.C.; Lamont, M.R.E.; Roelens, M.A.F.; Fu, L.; Eggleton, B.J. Low-threshold supercontinuum generation in highly nonlinear chalcogenide nanowires. Opt. Lett. 2008, 33, 660-662. [CrossRef] [PubMed]

97. Shaw, L.; Nguyen, V.; Sanghera, J.; Aggarwal, I.D.; Thielen, P.; Kung, F. IR Supercontinuum Generation in As-Se Photonic Crystal Fiber, Advanced Solid-State Photonics (TOPS); OSA Trends in Optics and Photonics; Optical Society of America: Washington, DC, USA, 2005.

98. Dawson, J.W.; Shaw, L.B.; Gattass, R.R.; Sanghera, J.; Aggarwal, I. All-fiber mid-IR supercontinuum source from 1.5 to $5 \mu \mathrm{m}$. Proc. SPIE 2011, 7914, 7914. [CrossRef]

99. Gattass, R.R.; Brandon Shaw, L.; Nguyen, V.Q.; Pureza, P.C.; Aggarwal, I.D.; Sanghera, J.S. All-fiber chalcogenide-based mid-infrared supercontinuum source. Opt. Fiber Technol. 2012, 18, 345-348. [CrossRef]

100. Geng, J.; Wang, Q.; Jiang, S. High-spectral-flatness mid-infrared supercontinuum generated from a Tm-doped fiber amplifier. Appl. Opt. 2012, 51, 834-840. [CrossRef] [PubMed]

101. Hilligsøe, K.M.; Paulsen, H.N.R.; Thøgersen, J.; Keiding, S.R.R.; Larsen, J.J. Initial steps of supercontinuum generation in photonic crystal fibers. J. Opt. Soc. Am. B 2003, 20, 1887-1893. [CrossRef]

102. Sakamaki, K.; Nakao, M.; Naganuma, M.; Izutsu, M. Soliton induced supercontinuum generation in photonic crystal fiber. IEEE J. Sel. Top. Quantum Electron. 2004, 10, 876-884. [CrossRef] 
103. Moeser, J.T.; Wolchover, N.A.; Knight, J.C.; Omenetto, F.G. Initial dynamics of supercontinuum generation in highly nonlinear photonic crystal fiber. Opt. Lett. 2007, 32, 952-954. [CrossRef] [PubMed]

104. Cheng, T.; Kanou, Y.; Asano, K.; Deng, D.; Liao, M.; Matsumoto, M.; Misumi, T.; Suzuki, T.; Ohishi, Y. Soliton self-frequency shift and dispersive wave in a hybrid four-hole $\mathrm{AsSe}_{2}-\mathrm{As}_{2} \mathrm{~S}_{5}$ microstructured optical fiber. Appl. Phys. Lett. 2014, 104, 662. [CrossRef]

105. Petersen, C.R.; Møller, U.; Kubat, I.; Zhou, B.; Dupont, S.; Ramsay, J.; Benson, T.; Sujecki, S.; Abdelmoneim, N.; Tang, Z. Mid-infrared supercontinuum covering the $1.4-13.3 \mu \mathrm{m}$ molecular fingerprint region using ultra-high NA chalcogenide step-index fibre. Nat. Photonics 2014, 8, 830-834. [CrossRef]

106. Herrmann, J.; Griebner, U.; Zhavoronkov, N.; Husakou, A.; Nickel, D.; Knight, J.C.; Wadsworth, W.J.; Russell, P.S.J.; Korn, G. Experimental evidence for supercontinuum generation by fission of higher-order solitons in photonic fibers. Phys. Rev. Lett. 2002, 88, 173901. [CrossRef] [PubMed]

107. Peng, Y.; Wang, W.; Wei, X.; Li, D. High-efficiency mid-infrared optical parametric oscillator based on ppmgo:Cln. Opt. Lett. 2009, 34, 2897-2899. [CrossRef] [PubMed]

108. Desmoulins, S.; Di Teodoro, F. Watt-level, high-repetition-rate, mid-infrared pulses generated by wavelength conversion of an eye-safe fiber source. Opt. Lett. 2007, 32, 56-58. [CrossRef] [PubMed]

109. Hudson, D.D.; Baudisch, M.; Werdehausen, D.; Eggleton, B.J.; Biegert, J. 1.9 octave supercontinuum generation in a $\mathrm{As}_{2} \mathrm{~s}_{3}$ step-index fiber driven by mid-IR OPCPA. Opt. Lett. 2014, 39, 5752-5755. [CrossRef] [PubMed]

110. Yu, Y.; Zhang, B.; Gai, X.; Zhai, C.; Qi, S.; Guo, W.; Yang, Z.; Wang, R.; Choi, D.-Y.; Madden, S.; et al. 1.8-10 $\mu \mathrm{m}$ mid-infrared supercontinuum generated in a step-index chalcogenide fiber using low peak pump power. Opt. Lett. 2015, 40, 1081-1084. [CrossRef] [PubMed]

111. Dantanarayana, H.G.; Abdel-Moneim, N.; Tang, Z.; Sojka, L.; Sujecki, S.; Furniss, D.; Seddon, A.B.; Kubat, I.; Bang, O.; Benson, T.M. Refractive index dispersion of chalcogenide glasses for ultra-high numerical-aperture fiber for mid-infrared supercontinuum generation. Opt. Mater. Express 2014, 4, 1444-1455. [CrossRef]

112. Luo, B.; Wang, Y.; Dai, S.; Sun, Y.N.; Zhang, P.; Wang, X.; Chen, F. Midinfrared supercontinuum generation in $\mathrm{As}_{2} \mathrm{Se}_{3}-\mathrm{As}_{2} \mathrm{~S}_{3}$ chalcogenide glass fiber with high NA. J. Lightwave Technol. 2017, 35, 2464-2469. [CrossRef]

113. Cheng, T.; Nagasaka, K.; Tuan, T.H.; Xue, X.; Matsumoto, M.; Tezuka, H.; Suzuki, T.; Ohishi, Y. Mid-infrared supercontinuum generation spanning 2.0 to $15.1 \mu \mathrm{m}$ in a chalcogenide step-index fiber. Opt. Lett. 2016, 41, 2117-2120. [CrossRef] [PubMed]

114. Ou, H.; Dai, S.; Zhang, P.; Liu, Z.; Wang, X.; Chen, F.; Xu, H.; Luo, B.; Huang, Y.; Wang, R. Ultrabroad supercontinuum generated from a highly nonlinear Ge-Sb-Se fiber. Opt. Lett. 2016, 41, 3201-3204. [CrossRef] [PubMed]

115. Wang, T.; Gai, X.; Wei, W.; Wang, R.; Yang, Z.; Shen, X.; Madden, S.; Luther-Davies, B. Systematic Z-scan measurements of the third order nonlinearity of chalcogenide glasses. Opt. Mater. Express 2014, 4, 1011. [CrossRef]

116. Wei, W.-H.; Wang, R.-P.; Shen, X.; Fang, L.; Luther-Davies, B. Correlation between structural and physical properties in Ge-Sb-Se glasses. J. Phys. Chem. C 2013, 117, 16571-16576. [CrossRef]

117. Zhang, B.; Yu, Y.; Zhai, C.; Qi, S.; Wang, Y.; Yang, A.; Gai, X.; Wang, R.; Yang, Z.; Luther-Davies, B. High brightness $2.2-12 \mu \mathrm{m}$ mid-infrared supercontinuum generation in a nontoxic chalcogenide step-index fiber. J. Am. Ceram. Soc. 2016, 99, 2565-2568. [CrossRef]

118. Wilhelm, A.A.; Boussard-Plédel, C.; Coulombier, Q.; Lucas, J.; Bureau, B.; Lucas, P. Development of far-infrared-transmitting Te based glasses suitable for carbon dioxide detection and space optics. Adv. Mater. 2007, 19, 3796-3800. [CrossRef]

119. Yang, Z.; Lucas, P. Tellurium-based far-infrared transmitting glasses. J. Am. Ceram. Soc. 2009, 92, $2920-2923$. [CrossRef]

120. Danto, S.; Houizot, P.; Boussard-Pledel, C.; Zhang, X.H.; Smektala, F.; Lucas, J. A family of far-infrared-transmitting glasses in the Ga-Ge-Te system for space applications. Adv. Funct. Mater. 2006, 16, 1847-1852. [CrossRef]

121. Yang, Z.; Luo, T.; Jiang, S.; Geng, J.; Lucas, P. Single-mode low-loss optical fibers for long-wave infrared transmission. Opt. Lett. 2010, 35, 3360-3362. [CrossRef] [PubMed]

122. Zhao, Z.; Wang, X.; Dai, S.; Pan, Z.; Liu, S.; Sun, L.; Zhang, P.; Liu, Z.; Nie, Q.; Shen, X.; et al. 1.5-14 $\mu \mathrm{m}$ midinfrared supercontinuum generation in a low-loss Te-based chalcogenide step-index fiber. Opt. Lett. 2016, 41, 5222-5225. [CrossRef] [PubMed] 
123. Conseil, C.; Bastien, J.-C.; Boussard-Plédel, C.; Zhang, X.-H.; Lucas, P.; Dai, S.; Lucas, J.; Bureau, B. Te-based chalcohalide glasses for far-infrared optical fiber. Opt. Mater. Express 2012, 2, 1470-1477. [CrossRef]

124. Wang, X.; Nie, Q.; Wang, G.; Sun, J.; Song, B.; Dai, S.; Zhang, X.; Bureau, B.; Boussard, C.; Conseil, C.; et al. Investigations of $\mathrm{Ge}-\mathrm{Te}-\mathrm{AgI}$ chalcogenide glass for far-infrared application. Spectrochim. Acta A 2012, 86, 586-589. [CrossRef] [PubMed]

125. Ogusu, K.; Shinkawa, K. Optical nonlinearities in $\mathrm{As}_{2} \mathrm{Se}_{3}$ chalcogenide glasses doped with $\mathrm{Cu}$ and $\mathrm{Ag}$ for pulse durations on the order of nanoseconds. Opt. Express 2009, 17, 8165-8172. [CrossRef] [PubMed]

126. Zhao, Z.; Wu, B.; Wang, X.; Pan, Z.; Liu, Z.; Zhang, P.; Shen, X.; Nie, Q.; Dai, S.; Wang, R. Mid-infrared supercontinuum covering 2.0-16 $\mathrm{m}$ in a low-loss telluride single-mode fiber. Laser Photonics Rev. 2017, 11, 1700005. [CrossRef]

127. Kedenburg, S.; Steinle, T.; Morz, F.; Steinmann, A.; Giessen, H. High-power mid-infrared high repetition-rate supercontinuum source based on a chalcogenide step-index fiber. Opt. Lett. 2015, 40, 2668-2671. [CrossRef] [PubMed]

128. Yao, J.; Zhang, B.; Yin, K.; Yang, L.; Hou, J.; Lu, Q. Mid-infrared supercontinuum generation in step-index $\mathrm{As}_{2} \mathrm{~S}_{3}$ fibers pumped by a nanosecond shortwave-infrared supercontinuum pump source. Opt. Express 2016, 24, 15093-15100. [CrossRef] [PubMed]

129. Wang, Y.; Dai, S.; Han, X.; Zhang, P.; Liu, Y.; Wang, X.; Sun, S. Broadband mid-infrared supercontinuum generation in novel $\mathrm{As}_{2} \mathrm{Se}_{3}-\mathrm{As}_{2} \mathrm{Se}_{2} \mathrm{~S}$ step-index fibers. Opt. Commun. 2018, 410, 410-415. [CrossRef]

130. Théberge, F.; Thiré, N.; Daigle, J.-F.; Mathieu, P.; Schmidt, B.E.; Messaddeq, Y.; Vallée, R.; Légaré, F. Multioctave infrared supercontinuum generation in large-core $\mathrm{As}_{2} \mathrm{~S}_{3}$ fibers. Opt. Lett. 2014, 39, 6474-6477. [CrossRef] [PubMed]

131. Troles, J.; Brilland, L.; Smektala, F.; Houizot, P.; Désévédavy, F.; Coulombier, Q.; Traynor, N.; Chartier, T.; Nguyen, T.N.; Adam, J.L. Chalcogenide microstructured fibers for infrared systems, elaboration modelization, and characterization. Fiber Integr. Opt. 2009, 28, 11-26. [CrossRef]

132. Monro, T.M.; West, Y.D.; Hewak, D.W.; Broderick, N.G.R.; Richardson, D.J. Chalcogenide holey fibres. Electron. Lett. 2000, 36, 1998-2000. [CrossRef]

133. Møller, U.; Yu, Y.; Kubat, I.; Petersen, C.R.; Gai, X.; Brilland, L.; Méchin, D.; Caillaud, C.; Troles, J.; Luther-Davies, B.; et al. Multi-milliwatt mid-infrared supercontinuum generation in a suspended core chalcogenide fiber. Opt. Express 2015, 23, 3282-3291. [CrossRef] [PubMed]

134. Baili, A.; Cherif, R.; Zghal, M. Two octaves spanning supercontinuum in highly nonlinear AsSe nanophotonic crystal fiber for midinfrared applications. J. Nanophotonics 2016, 9, 618-623.

135. Saini, T.S.; Kumar, A.; Sinha, R.K. Broadband mid-ir supercontinuum generation in $\mathrm{As}_{2} \mathrm{Se}_{3}$ based chalcogenide photonic crystal fiber: A new design and analysis. Opt. Commun. 2015, 347, 13-19. [CrossRef]

136. Lee, K.F.; Granzow, N.; Schmidt, M.A.; Chang, W.; Wang, L.; Coulombier, Q.; Troles, J.; Leindecker, N.; Vodopyanov, K.L.; Schunemann, P.G.; et al. Midinfrared frequency combs from coherent supercontinuum in chalcogenide and optical parametric oscillation. Opt. Lett. 2014, 39, 2056-2059. [CrossRef] [PubMed]

137. Granzow, N.; Schmidt, M.A.; Chang, W.; Wang, L.; Coulombier, Q.; Troles, J.; Toupin, P.; Hartl, I.; Lee, K.F.; Fermann, M.E.; et al. Mid-infrared supercontinuum generation in $\mathrm{As}_{2} \mathrm{~S}_{3}$-silica "nano-spike" step-index waveguide. Opt. Express 2013, 21, 10969-10977. [CrossRef] [PubMed]

138. Granzow, N.; Stark, S.P.; Schmidt, M.A.; Tverjanovich, A.S.; Wondraczek, L.; Russell, P.S.J. Supercontinuum generation in chalcogenide-silica step-index fibers. Opt. Express 2011, 19, 21003-21010. [CrossRef] [PubMed]

139. Diouf, M.; Salem, A.B.; Cherif, R.; Wague, A.; Zghal, M. A novel As ${ }_{2} \mathrm{~S}_{5}$-tellurite hybrid photonic crystal fiber for long mid-IR supercontinuum fiber lasers. In Proceedings of the SPIE Optical Engineering + Applications, San Diego, CA, USA, 9-13 August 2015.

140. Maji, P.S.; Chaudhuri, P.R. Design of all-normal dispersion based on multi-material photonic crystal fiber in IR region for broadband supercontinuum generation. Appl. Opt. 2015, 54, 4042-4048. [CrossRef]

141. Jamatia, P.; Saini, T.S.; Kumar, A.; Sinha, R.K. Design and analysis of a highly nonlinear composite photonic crystal fiber for supercontinuum generation: Visible to mid-infrared. Appl. Opt. 2016, 55, 6775-6781. [CrossRef] [PubMed]

142. Cheng, T.; Kawashima, H.; Xue, X.; Deng, D.; Matsumoto, M.; Misumi, T.; Suzuki, T.; Ohishi, Y. Fabrication of a chalcogenide-tellurite hybrid microstructured optical fiber for flattened and broadband supercontinuum generation. J. Lightwave Technol. 2015, 33, 333-338. [CrossRef] 
143. Salem, A.B.; Diouf, M.; Cherif, R.; Wague, A.; Zghal, M. Ultraflat-top midinfrared coherent broadband supercontinuum using all normal $\mathrm{As}_{2} \mathrm{~S}_{5}$-borosilicate hybrid photonic crystal fiber. Opt. Eng. 2016, 55, 066109. [CrossRef]

144. Savelli, I.; Mouawad, O.; Fatome, J.; Kibler, B.; Désévédavy, F.; Gadret, G.; Jules, J.C.; Bony, P.Y.; Kawashima, H.; Gao, W.; et al. Mid-infrared 2000-nm bandwidth supercontinuum generation in suspended-core microstructured sulfide and tellurite optical fibers. Opt. Express 2012, 20, 27083-27093. [CrossRef] [PubMed]

145. Gris-Sanchez, I.; Knight, J.C. Time-dependent degradation of photonic crystal fiber attenuation around oh absorption wavelengths. J. Lightwave Technol. 2012, 30, 3597-3602. [CrossRef]

146. Mouawad, O.; Strutynski, C.; Picot-Clémente, J.; Désévédavy, F.; Gadret, G.; Jules, J.C.; Smektala, F. Optical aging behaviour naturally induced on $\mathrm{As}_{2} \mathrm{~S}_{3}$ microstructured optical fibres. Opt. Mater. Express 2014, 4, 2190-2203. [CrossRef]

147. Mouawad, O.; Amrani, F.; Kibler, B.; Picot-Clémente, J.; Strutynski, C.; Fatome, J.; Désévédavy, F.; Gadret, G.; Jules, J.C.; Heintz, O.; et al. Impact of optical and structural aging in $\mathrm{As}_{2} \mathrm{~S}_{3}$ microstructured optical fibers on mid-infrared supercontinuum generation. Opt. Express 2014, 22, 23912-23919. [CrossRef] [PubMed]

148. Rudy, C.W.; Marandi, A.; Vodopyanov, K.L.; Byer, R.L. Octave-spanning supercontinuum generation in in situ tapered $\mathrm{As}_{2} \mathrm{~S}_{3}$ fiber pumped by a thulium-doped fiber laser. Opt. Lett. 2013, 38, 2865-2868. [CrossRef] [PubMed]

149. Petersen, C.R.; Engelsholm, R.D.; Markos, C.; Brilland, L.; Caillaud, C.; Trolès, J.; Bang, O. Increased mid-infrared supercontinuum bandwidth and average power by tapering large-mode-area chalcogenide photonic crystal fibers. Opt. Express 2017, 25, 15336-15348. [CrossRef] [PubMed]

150. Birks, T.A.; Wadsworth, W.J.; Russell, P.S.J. Supercontinuum generation in tapered fibers. Opt. Lett. 2000, 25, 1415-1417. [CrossRef] [PubMed]

151. Shabahang, S.; Tao, G.; Marquez, M.P.; Hu, H.; Ensley, T.R.; Delfyett, P.J.; Abouraddy, A.F. Nonlinear characterization of robust multimaterial chalcogenide nanotapers for infrared supercontinuum generation. J. Opt. Soc. Am. B 2014, 31, 450-457. [CrossRef]

152. Wang, F.; Wang, K.; Yao, C.; Jia, Z.; Wang, S.; Wu, C.; Qin, G.; Ohishi, Y.; Qin, W. Tapered fluorotellurite microstructured fibers for broadband supercontinuum generation. Opt. Lett. 2016, 41, 634-637. [CrossRef] [PubMed]

153. Wang, Y.; Dai, S.; Li, G.; Xu, D.; You, C.; Han, X.; Zhang, P.; Wang, X.; Xu, P. 1.4-7.2 $\mu$ m broadband supercontinuum generation in an As-S chalcogenide tapered fiber pumped in the normal dispersion regime. Opt. Lett. 2017, 42, 3458-3461. [CrossRef] [PubMed]

154. Luo, B.; Wang, Y.; Sun, Y.N.; Dai, S.; Yang, P.; Zhang, P.; Wang, X.; Chen, F.; Wang, R. Fabrication and characterization of bare Ge-Sb-Se chalcogenide glass fiber taper. Infrared Phys. Technol. 2017, 80, 105-111. [CrossRef]

155. Hartl, I.; Li, X.D.; Chudoba, C.; Ghanta, R.K.; Ko, T.H.; Fujimoto, J.G.; Ranka, J.K.; Windeler, R.S. Ultrahigh-resolution optical coherence tomography using continuum generation in an air-silica microstructure optical fiber. Opt. Lett. 2001, 26, 608-610. [CrossRef] [PubMed]

156. Rothhardt, J.; Heidt, A.M.; Hädrich, S.; Demmler, S.; Limpert, J.; Tünnermann, A. High stability soliton frequency-shifting mechanisms for laser synchronization applications. J. Opt. Soc. Am. B 2012, 29, 1257-1262. [CrossRef]

157. Udem, T.; Holzwarth, R.; Hänsch, T.W. Optical frequency metrology. Nature 2002, 416, 233-237. [CrossRef] [PubMed]

158. Paulsen, H.N.; Hilligse, K.M.; Thøgersen, J.; Keiding, S.R.; Larsen, J.J. Coherent anti-stokes raman scattering microscopy with a photonic crystal fiber based light source. Opt. Lett. 2003, 28, 1123-1125. [CrossRef] [PubMed]

159. Dudley, J.M.; Coen, S. Coherence properties of supercontinuum spectra generated in photonic crystal and tapered optical fibers. Opt. Lett. 2002, 27, 1180-1182. [CrossRef] [PubMed]

160. Genty, G.; Surakka, M.; Turunen, J.; Friberg, A.T. Second-order coherence of supercontinuum light. Opt. Lett. 2010, 35, 3057-3059. [CrossRef] [PubMed]

161. Genty, G.; Surakka, M.; Turunen, J.; Friberg, A.T. Complete characterization of supercontinuum coherence. J. Opt. Soc. Am. B 2011, 28, 2301-2309. [CrossRef] 
162. Corwin, K.L.; Newbury, N.R.; Dudley, J.M.; Coen, S.; Diddams, S.A.; Weber, K.; Windeler, R.S. Fundamental noise limitations to supercontinuum generation in microstructure fiber. Phys. Rev. Lett. 2003, 90, 113904. [CrossRef] [PubMed]

163. Sørensen, S.T.; Larsen, C.; Møller, U.; Moselund, P.M.; Thomsen, C.L.; Bang, O. Influence of pump power and modulation instability gain spectrum on seeded supercontinuum and rogue wave generation. J. Opt. Soc. Am. B 2012, 29, 2875-2885. [CrossRef]

164. Li, N.; Wang, F.; Yao, C.; Jia, Z.; Zhang, L.; Feng, Y.; Hu, M.; Qin, G.; Ohishi, Y.; Qin, W. Coherent supercontinuum generation from 1.4 to $4 \mu \mathrm{m}$ in a tapered fluorotellurite microstructured fiber pumped by a $1980 \mathrm{~nm}$ femtosecond fiber laser. Appl. Phys. Lett. 2017, 110, 061102. [CrossRef]

165. Hooper, L.E.; Mosley, P.J.; Muir, A.C.; Wadsworth, W.J.; Knight, J.C. Coherent supercontinuum generation in photonic crystal fiber with all-normal group velocity dispersion. Opt. Express 2011, 19, 4902-4907. [CrossRef] [PubMed]

166. Heidt, A.M.; Hartung, A.; Bosman, G.W.; Krok, P.; Rohwer, E.G.; Schwoerer, H.; Bartelt, H. Coherent octave spanning near-infrared and visible supercontinuum generation in all-normal dispersion photonic crystal fibers. Opt. Express 2011, 19, 3775-3787. [CrossRef] [PubMed]

167. Heidt, A.M. Pulse preserving flat-top supercontinuum generation in all-normal dispersion photonic crystal fibers. J. Opt. Soc. Am. B 2010, 27, 550-559. [CrossRef]

168. Liu, L.; Cheng, T.; Nagasaka, K.; Tong, H.; Qin, G.; Suzuki, T.; Ohishi, Y. Coherent mid-infrared supercontinuum generation in all-solid chalcogenide microstructured fibers with all-normal dispersion. Opt. Lett. 2016, 41, 392-395. [CrossRef] [PubMed]

169. Siwicki, B.; Filipkowski, A.; Kasztelanic, R.; Klimczak, M.; Buczyński, R. Nanostructured graded-index core chalcogenide fiber with all-normal dispersion-design and nonlinear simulations. Opt. Express 2017, 25, 12984-12998. [CrossRef] [PubMed]

170. Falk, P.; Frosz, M.H.; Bang, O. Supercontinuum generation in a photonic crystal fiber with two zero-dispersion wavelengths tapered to normal dispersion at all wavelengths. Opt. Express 2005, 13, 7535-7540. [CrossRef] [PubMed]

171. Liu, L.; Nagasaka, K.; Qin, G.; Suzuki, T.; Ohishi, Y. Coherence property of mid-infrared supercontinuum generation in tapered chalcogenide fibers with different structures. Appl. Phys. Lett. 2016, 108, 011101. [CrossRef]

172. Hilligsøe, K.M.; Andersen, T.V.; Paulsen, H.N.; Nielsen, C.K.; Mølmer, K.; Keiding, S.; Kristiansen, R.; Hansen, K.P.; Larsen, J.J. Supercontinuum generation in a photonic crystal fiber with two zero dispersion wavelengths. Opt. Express 2004, 12, 1045-1054. [CrossRef] [PubMed]

173. Diouf, M.; Salem, A.B.; Cherif, R.; Saghaei, H.; Wague, A. Super-flat coherent supercontinuum source in $\mathrm{As}_{38.8} \mathrm{Se}_{61.2}$ chalcogenide photonic crystal fiber with all-normal dispersion engineering at a very low input energy. Appl. Opt. 2017, 56, 163-169. [CrossRef] [PubMed]

174. Andresen, E.R.; Paulsen, H.N.; Birkedal, V.; Thøgersen, J.; Keiding, S.R. Broadband multiplex coherent anti-stokes raman scattering microscopy employing photonic-crystal fibers. J. Opt. Soc. Am. B 2005, 22, 1934-1938. [CrossRef]

175. Wei, C.; Shi, H.; Luo, H.; Zhang, H.; Lyu, Y.; Liu, Y. 34 nm-wavelength-tunable picosecond $\mathrm{Ho}^{3+} / \mathrm{Pr}^{3+}$-codoped ZBLAN fiber laser. Opt. Express 2017, 25, 19170-19178. [CrossRef] [PubMed]

176. Shen, Y.; Wang, Y.; Chen, H.; Luan, K.; Tao, M.; Si, J. Wavelength-tunable passively mode-locked mid-infrared $\mathrm{Er}^{3+}$-doped zblan fiber laser. Sci. Rep. 2017, 7, 14913. [CrossRef] [PubMed]

177. Antipov, S.; Hudson, D.D.; Fuerbach, A.; Jackson, S.D. High-power mid-infrared femtosecond fiber laser in the water vapor transmission window. Optica 2016, 3, 1373-1376. [CrossRef]

178. Duval, S.; Bernier, M.; Fortin, V.; Genest, J.; Piché, M.; Vallée, R. Femtosecond fiber lasers reach the mid-infrared. Optica 2015, 2, 623-626. [CrossRef]

179. Henderson-Sapir, O.; Munch, J.; Ottaway, D.J. Mid-infrared fiber lasers at and beyond $3.5 \mu \mathrm{m}$ using dual-wavelength pumping. Opt. Lett. 2014, 39, 493-496. [CrossRef] [PubMed]

180. Schneide, J.; Carbonnier, C.; Unrau, U.B. Characterization of a $\mathrm{Ho}^{3+}$-doped fluoride fiber laser with a 3.9- $\mu \mathrm{m}$ emission wavelength. Appl. Opt. 1997, 36, 8595-8600. [CrossRef]

181. Hudson, D.D.; Antipov, S.; Li, L.; Alamgir, I.; Hu, T.; Amraoui, M.E.; Messaddeq, Y.; Rochette, M.; Jackson, S.D.; Fuerbach, A. Toward all-fiber supercontinuum spanning the mid-infrared. Optica 2017, 4, 1163-1166. [CrossRef] 
182. Dudley, J.M.; Taylor, J.R. Supercontinuum Generation in Optical Fibers; Cambridge University Press: Cambridge, UK, 2010; pp. 619-627.

183. Bernier, M.; Fortin, V.; Caron, N.; El-Amraoui, M.; Messaddeq, Y.; Vallée, R. Mid-infrared chalcogenide glass Raman fiber laser. Opt. Lett. 2013, 38, 127-129. [CrossRef] [PubMed]

184. Bernier, M.; Fortin, V.; El-Amraoui, M.; Messaddeq, Y.; Vallée, R. $3.77 \mu \mathrm{m}$ fiber laser based on cascaded Raman gain in a chalcogenide glass fiber. Opt. Lett. 2014, 39, 2052-2055. [CrossRef] [PubMed]

185. Fortin, V.; Bernier, M.; Caron, N.; Faucher, D.; El-Amraoui, M.; Messaddeq, Y.; Vallee, R. Towards the development of fiber lasers for the 2 to $4 \mu \mathrm{m}$ spectral region. Opt. Eng. 2013, 52, 054202. [CrossRef]

186. Islam, M.N. Mid-Infrared Fiber Laser Using Cascaded Raman Wavelength Shifting. U.S. Patent US8036252B2, 11 October 2011.

187. Kubat, I.; Petersen, C.R.; Møller, U.V.; Seddon, A.; Benson, T.; Brilland, L.; Méchin, D.; Moselund, P.M.; Bang, O. Thulium pumped mid-infrared 0.9-9 $\mu \mathrm{m}$ supercontinuum generation in concatenated fluoride and chalcogenide glass fibers. Opt. Express 2014, 22, 3959-3967. [CrossRef] [PubMed]

188. Robichaud, L.-R.; Fortin, V.; Gauthier, J.-C.; Châtigny, S.; Couillard, J.-F.; Delarosbil, J.-L.; Vallée, R.; Bernier, M. Compact 3-8 $\mu \mathrm{m}$ supercontinuum generation in a low-loss $\mathrm{As}_{2} \mathrm{Se}_{3}$ step-index fiber. Opt. Lett. 2016, 41, 4605-4608. [CrossRef] [PubMed]

189. Petersen, C.R.; Moselund, P.M.; Petersen, C.; Møller, U.; Bang, O. Spectral-temporal composition matters when cascading supercontinua into the mid-infrared. Opt. Express 2016, 24, 749-758. [CrossRef] [PubMed]

190. Yin, K.; Zhang, B.; Yang, L.; Hou, J. $15.2 \mathrm{w}$ spectrally flat all-fiber supercontinuum laser source with $>1 \mathrm{w}$ power beyond $3.8 \mu \mathrm{m}$. Opt. Lett. 2017, 42, 2334-2337. [CrossRef] [PubMed]

191. Kneis, C.; Donelan, B.; Manek-Hönninger, I.; Robin, T.; Cadier, B.; Brilland, L.; Troles, J.; Caillaud, C.; Eichhorn, M.; Kieleck, C. Mid-infrared supercontinuum generation from cascaded soft-glass. In Proceedings of the High-Brightness Sources and Light-Driven Interactions, Long Beach, CA, USA, 20-22 March 2016.

192. Yang, W.; Zhang, B.; Xue, G.; Yin, K.; Hou, J. Thirteen watt all-fiber mid-infrared supercontinuum generation in a single mode zblan fiber pumped by a $2 \mu \mathrm{m}$ MOPA system. Opt. Lett. 2014, 39, 1849-1852. [CrossRef] [PubMed]

193. Liu, K.; Liu, J.; Shi, H.; Tan, F.; Wang, P. High power mid-infrared supercontinuum generation in a single-mode ZBLAN fiber with up to $21.8 \mathrm{~W}$ average output power. Opt. Express 2014, 22, 24384-24391. [CrossRef] [PubMed]

194. Yin, K.; Zhang, B.; Yao, J.; Cai, Z.; Liu, G.; Hou, J. Toward high-power all-fiber 2-5 $\mu$ m supercontinuum generation in chalcogenide step-index fiber. J. Lightwave Technol. 2017, 35, 4535-4539. [CrossRef]

195. Martinez, R.A.; Plant, G.; Guo, K.; Janiszewski, B.; Freeman, M.J.; Maynard, R.L.; Islam, M.N.; Terry, F.L.; Alvarez, O.; Chenard, F; et al. Mid-infrared supercontinuum generation from 1.6 to $>11 \mu \mathrm{m}$ using concatenated step-index fluoride and chalcogenide fibers. Opt. Lett. 2018, 43, 296-299. [CrossRef] [PubMed]

196. Thapa, R.; Gattass, R.R.; Nguyen, V.; Chin, G.; Gibson, D.; Kim, W.; Shaw, L.B.; Sanghera, J.S. Low-loss, robust fusion splicing of silica to chalcogenide fiber for integrated mid-infrared laser technology development. Opt. Lett. 2015, 40, 5074-5077. [CrossRef] [PubMed]

197. Yin, K.; Zhang, B.; Yao, J.; Yang, L.; Chen, S.; Hou, J. Highly stable, monolithic, single-mode mid-infrared supercontinuum source based on low-loss fusion spliced silica and fluoride fibers. Opt. Lett. 2016, 41, 946-949. [CrossRef] [PubMed]

198. Okamoto, H.; Kasuga, K.; Kubota, Y. Efficient $521 \mathrm{~nm}$ all-fiber laser: Splicing $\mathrm{Pr}^{3+}$-doped ZBLAN fiber to end-coated silica fiber. Opt. Lett. 2011, 36, 1470-1472. [CrossRef] [PubMed]

(c) 2018 by the authors. Licensee MDPI, Basel, Switzerland. This article is an open access article distributed under the terms and conditions of the Creative Commons Attribution (CC BY) license (http://creativecommons.org/licenses/by/4.0/). 